\title{
Latanoprost in the treatment of glaucoma
}

This article was published in the following Dove Press journal:

Clinical Ophthalmology

26 September 2014

Number of times this article has been viewed

\begin{abstract}
Albert Alm
Department of Neuroscience, Ophthalmology, University Hospital, Uppsala, Sweden
\end{abstract}

Abstract: Prostaglandins are approved by the European Glaucoma Society guidelines as firstline treatment for glaucoma. This review focuses on latanoprost, an ester prodrug of prostaglandin (PG) $\mathrm{F}_{2 \alpha}$, which was the first of the currently available topical PGF $_{2 \alpha}$ analogs to be launched for glaucoma or ocular hypertension and which still accounts for the majority of prescriptions. It is better absorbed than the parent compound through the cornea, and peak concentration of the active drug is in the aqueous humor 1-2 hours after topical dosing (15-30 ng/mL). Metabolism occurs mainly in the liver. Latanoprost $(0.005 \%)$ has been very well studied in clinical trials and meta-analyses that show it to be generally as effective as the other PG analogs (bimatoprost, travoprost, and tafluprost) and more effective than timolol, dorzolamide, and brimonidine. Latanoprost has good short- and long-term safety and tolerability profiles. In common with other prostaglandins, it lacks systemic effects, but can cause ocular adverse events such as conjunctival hyperemia, pigmentation of the iris, periocular skin or eyelashes, hypertrichosis, and ocular surface effects or irritation. Latanoprost is significantly better tolerated than either bimatoprost or travoprost. Patients treated with latanoprost have better compliance and persist with therapy longer than those that are given other drugs. An improved formulation of latanoprost without the preservative benzalkonium chloride has recently been developed. It is as effective as conventional latanoprost, has a lower incidence of hyperemia, and can be stored at room temperature. In conclusion, latanoprost has the best efficacy-tolerability ratio of the PG analogs available for glaucoma treatment, and has good compliance and persistence. These factors should be improved further by the recent development of preservative-free latanoprost.

Keywords: prostaglandin, intraocular pressure, ocular hypertension, hyperemia, glaucoma, latanoprost

\section{Introduction}

One of the major risk factors for the development and progression of glaucoma is elevated intraocular pressure (IOP). ${ }^{1,2}$ Topical prostaglandins (PGs), with their powerful ocular hypotensive effect (which is mainly the result of increasing uveoscleral outflow), are therefore an important treatment option for glaucoma. ${ }^{3}$

PGs/prostamides are approved as the first-line treatment for glaucoma in the European Glaucoma Society guidelines. ${ }^{4}$ The main reasons for this choice include their IOP-lowering efficacy, their lack of relevant systemic side effects, their requirement for only once-daily dosing, and their good overall tolerability profile.

This review focuses on the use of latanoprost, an ester prodrug of prostaglandin $\mathrm{F}_{2 \alpha}\left(\mathrm{PGF}_{2 \alpha}\right)$, in the management of glaucoma. Latanoprost was the first of the currently available topical $\mathrm{PGF}_{2 \alpha}$ analogs to be launched for glaucoma treatment, and it
Correspondence: Albert Alm Department of Neuroscience (Ophthalmology), Uppsala University Biomedical Centre, Husargarten 3, SE-75I 24, Uppsala, Sweden

Tel +46 I86 II5 I35

Email albert.alm@akademiska.se 
still accounts for the majority of PG-analog prescriptions due to its good efficacy-tolerability profile. It was also the first PG analog to have generics developed, and an improved formulation has recently been produced without benzalkonium chloride (BAK).

Publications to be considered for inclusion in this review were selected in PubMed using the search terms "latanoprost", "glaucoma/drug therapy*[MeSH]", "metaanalysis[publication type]", "comparative study[publication type]", and "patient compliance[MeSH]". More recent studies that were yet to be indexed were identified from ad hoc searches and the author's own database.

\section{Prostaglandins}

PGs were initially isolated from prostate tissue in $1935 .^{5}$ They are now known to be produced by almost all nucleated cells. They are a family of lipid compounds that are derived enzymatically from essential fatty acids,${ }^{6}$ with each one containing 20 carbon atoms, including a 5-carbon ring. They act locally as autocrine or paracrine mediators with a wide range of effects throughout the body.

\section{Effects of prostaglandins in ophthalmology and development for glaucoma treatment}

Several PGs are naturally synthesized in the iris and ciliary body and are released following trauma to the eye. ${ }^{7}$ One of the PGs that is released is $\mathrm{PGF}_{2 \alpha}$, which is now known to cause a powerful reduction in IOP. Animal studies have shown that this hypotensive activity is mainly due to an enhanced uveoscleral outflow, with minor effects on trabecular outflow and aqueous flow. ${ }^{3}$ One potential mechanism behind this enhanced outflow is the regulation of matrix metalloproteinases and remodeling of the extracellular matrix, which changes the permeability of tissues associated with the outflow pathways resulting in alterations in outflow resistance and/or outflow rates. ${ }^{3}$

Discovery of the effect of PGs on IOP led to the development of PG analogs as a potential glaucoma treatment. Initial research focused on $\mathrm{PGF}_{2 \alpha}$. The initial steps included esterification of the carboxylic acid of $\mathrm{PGF}_{2 \alpha}$ to improve corneal penetration and reduce side effects. ${ }^{8}$ One of the most promising of these prodrugs of $\mathrm{PGF}_{2 \alpha}$ was the isopropyl ester form. However, despite having excellent pharmacokinetic properties, it still caused unacceptable foreign-body sensation and conjunctival hyperemia. ${ }^{9} 10$ Modification of the omega chain of this molecule led to improved selectivity for PGF receptors and a greatly improved tolerability profile. ${ }^{11}$ This molecule was subsequently known as latanoprost and underwent clinical development as a treatment for glaucoma. Later studies in knock-out mice showed that intact PGF and $\mathrm{PGE}_{3}$ receptors were necessary for IOP reduction. ${ }^{12,13}$

\section{Latanoprost}

Latanoprost (0.005\%) was launched in 1996 and was the first of the currently available topical $\mathrm{PGF}_{2 \alpha}$ analogs on the market for glaucoma treatment. Later introductions included travoprost $(0.004 \%)$, bimatoprost $(0.03 \%)$, and, most recently, tafluprost $(0.0015 \%)$. Latanoprost still accounts for approximately $65 \%$ of PG-analog prescriptions.

\section{Pharmacokinetics}

Latanoprost is an esterified prodrug of $\mathrm{PGF}_{2 \alpha}$ and, as such, is more lipophilic than the parent compound..$^{11}$ This means that it is better absorbed through the cornea, where it is undergoes hydrolysis to latanoprost acid. In adult humans, peak concentration of the active drug was detected in the aqueous humor 1-2 hours after topical dosing and amounted to $15-30 \mathrm{ng} / \mathrm{mL} .{ }^{14}$ In the systemic circulation, the peak concentration occurred after 5 minutes and reached a level of $53 \mathrm{pg} / \mathrm{mL}$. The elimination half-life was $2-3$ hours from the eye and 17 minutes from the circulation. The median peak plasma concentration and area under the concentration-time curve after adult dosing were found to be higher in infants less than 3 years old than in older subjects, primarily due to lower body weight and smaller blood volume; but latanoprost acid was rapidly eliminated in all age groups. ${ }^{15}$

Metabolism mainly occurs in the liver where latanoprost acid undergoes beta-oxidation to 1,2-dinor and 1,2,3,4-tetranor latanoprost acid, the main metabolites of latanoprost. ${ }^{14}$ The majority of the dose is excreted via the urine (88\%) with the remainder being recovered in the feces.

The reduction in IOP seen with latanoprost begins after 3-4 hours, reaches a maximum after $8-12$ hours, and is maintained for at least 24 hours. ${ }^{16}$

\section{Efficacy}

Latanoprost has been very well studied, with numerous publications of clinical trials, meta-analyses, and reviews. ${ }^{17}$ Initial studies showed once-daily topical latanoprost $(0.005 \%)$ to be safe and effective in the short- and long-term treatment of glaucoma or ocular hypertension. A review of three masked multicenter Phase III studies in 829 patients with elevated IOP in Scandinavia, the USA, and the UK showed that 6 months treatment with latanoprost reduced IOP by $35 \%$, if given in the evening, and by $31 \%$, if given in the morning. ${ }^{18}$ Conjunctival hyperemia and darkening of the 
iris color were the only notable side effects. Subsequently, darker and longer eye lashes were also reported. ${ }^{19}$ Later open studies conducted over 2 years reported that the reduction in IOP was maintained during long-term treatment and no other clinically significant side effects developed. ${ }^{20,21}$ Similarly good results were reported in 5-year studies, although the main focus was on safety and tolerability. ${ }^{22-24}$

\section{Latanoprost versus other prostaglandins Bimatoprost}

Latanoprost has been extensively compared with bimatoprost in randomized controlled trials. One of the largest of these involved 411 patients with open-angle glaucoma or ocular hypertension treated for 12 weeks with latanoprost, bimatoprost, or travoprost. ${ }^{25}$ At the end of the study, there was a significant $(P<0.001)$ reduction in 8 am IOP in all groups. The estimated mean reduction was $8.6 \pm 0.3 \mathrm{mmHg}$ with latanoprost and $8.7 \pm 0.3 \mathrm{mmHg}$ with bimatoprost. The adjusted differences in mean IOP reductions at 8 am also showed equivalence between latanoprost and bimatoprost (0.13 mmHg; 95\% confidence interval [CI] 0.84-0.58). No significant differences were observed between the two treatments in IOP reduction at noon, $4 \mathrm{pm}$, and $8 \mathrm{pm}$, or in changes in mean diurnal IOP levels. A subsequent study in 48 patients with open-angle glaucoma also failed to find statistically significant differences between latanoprost and bimatoprost in IOP reductions at $8 \mathrm{am}, 10 \mathrm{am}, 1 \mathrm{pm}, 4 \mathrm{pm}$, 8 pm, 11 pm, and 3 am after 8 weeks of treatment. ${ }^{26}$

One double-blind, crossover study focused on circadian IOP in 44 patients with open-angle glaucoma or ocular hypertension. ${ }^{27}$ After 1 month, latanoprost and bimatoprost were equally effective in reducing IOP, with no significant differences between them, and the authors concluded that they were both powerful agents in controlling around-theclock IOP. A more recent crossover study assessed IOP reduction in 54 patients with angle-closure glaucoma treated with latanoprost or bimatoprost for 6 weeks. ${ }^{28}$ At the end of treatment, mean IOP was reduced by $8.4 \pm 3.8 \mathrm{mmHg}$ with latanoprost and $8.9 \pm 3.9 \mathrm{mmHg}$ with bimatoprost, with no significant differences between the groups.

Some discrepancies have been reported in other studies, however, with bimatoprost being significantly more effective than latanoprost at certain time points. An older study in 232 patients with glaucoma or ocular hypertension found that bimatoprost reduced IOP significantly more than latanoprost at noon $(P=0.021)$, but not at 8 am (primary efficacy parameter), 4 pm, or 8 pm after 3 months of treatment. ${ }^{29}$ In another double-blind study, no statistically significant differences in IOP reduction were seen between latanoprost $(20 \%-31 \%)$ and bimatoprost $(26 \%-34 \%)$ at any time point measured on day 14 or 29 in 64 patients with open-angle glaucoma or ocular hypertension. ${ }^{30}$ However, on day 29 , bimatoprost had a significantly $(P=0.0378)$ larger area under the curve for IOP reduction. Similarly, in a 7-week double-blind crossover study in 44 patients with open-angle glaucoma, bimatoprost was significantly more effective than latanoprost regarding diurnal curve IOP only at $6 \mathrm{pm}(P=0.008$ after Bonferroni correction), but not at 2 am, 6 am, 10 am, 2 pm, or 10 pm. ${ }^{31}$ The mean 24 hour IOP was also significantly $(P=0.01)$ lower with bimatoprost $(16.7 \pm 2.4 \mathrm{mmHg})$ than latanoprost $(17.3 \pm 2.8 \mathrm{mmHg})$. Significant between-group differences in mean IOP reduction in favor of bimatoprost were seen at 8 am $(P \leq 0.033)$, but not at noon or $4 \mathrm{pm}$, in a 3-month double-blind trial in 60 patients with normal tension glaucoma. ${ }^{32}$ In contrast to these findings, a 6-month study involving 269 patients with glaucoma or ocular hypertension showed bimatoprost to be significantly $(P<0.004)$ more effective than latanoprost in reducing IOP at all time points measured ( $8 \mathrm{am}$, noon, and $4 \mathrm{pm}) .{ }^{33}$

Recent studies have evaluated the effects of latanoprost on central corneal thickness, which allows for a more accurate estimate of IOP. ${ }^{34,35}$ Central corneal thickness was significantly $(P<0.001)$ reduced by latanoprost $(-14.95 \pm 5.04 \mu \mathrm{m})$ and bimatoprost $(-17.00 \pm 6.23 \mu \mathrm{m})$ after a mean follow-up of 17 months in 69 patients with glaucoma or ocular hypertension. ${ }^{36}$ The duration of treatment had no effect, with a lack of significant difference being seen in patients treated for $\leq 6$ months as well as those treated for $>6$ months.

In summary, the considerable amount of data available indicates that latanoprost is equally as effective as bimatoprost. Some studies have shown small advantages for bimatoprost at certain time points, although there appears to be no consistency in these findings. There is some evidence to suggest that bimatoprost is hydrolyzed to its free acid, a potent PG F receptor agonist, in sufficient levels in the aqueous humor to account for at least some of its ability to reduce IOP. ${ }^{37}$

\section{Travoprost}

As with bimatoprost, a considerable number of randomized controlled trials have compared travoprost and latanoprost. In a 12-week trial in 411 patients with open-angle glaucoma or ocular hypertension, the estimated mean reduction in $8 \mathrm{am} \mathrm{IOP}$ at the end of treatment was $8.6 \pm 0.3 \mathrm{mmHg}$ with latanoprost and $8.0 \pm 0.3 \mathrm{mmHg}$ with travoprost. ${ }^{25}$ The 
adjusted differences in mean 8 am IOP reductions also showed no significant difference between latanoprost and travoprost (0.56 mmHg; 95\% CI 0.15-1.26) as did all secondary efficacy parameters. Similarly, a 1-month double-blind crossover study in 44 patients with open-angle glaucoma or ocular hypertension showed no statistically significant difference between latanoprost and travoprost in circadian IOP reduction. ${ }^{27} \mathrm{~A}$ study in 48 patients with open-angle glaucoma reported no significant differences in efficacy on overall diurnal IOP between latanoprost and travoprost (and bimatoprost that was also included in the study), but significantly greater IOP reductions at 8 am and $10 \mathrm{am}$, but not at $1 \mathrm{pm}, 4 \mathrm{pm}, 8 \mathrm{pm}, 11 \mathrm{pm}$, and $3 \mathrm{am}$, after 8 weeks of treatment with travoprost versus latanoprost or bimatoprost. ${ }^{26}$ A more recent double-blind study in 302 patients with openangle glaucoma or ocular hypertension found no statistically significant differences in IOP values after 6 weeks' treatment with travoprost $\left(16.1 \mathrm{mmHg}\right.$ ) or latanoprost $(16.4 \mathrm{mmHg}){ }^{38}$ The pooled changes in IOP from baseline after 1, 2, 4, and 6 weeks of treatment did, however, show a significant difference in favor of travoprost $(-8.3 \mathrm{mmHg}$ versus $-7.5 \mathrm{mmHg}$; $P=0.009$ ). IOP was measured at $5 \mathrm{pm}, 20$ hours after drug administration. In 69 patients with glaucoma or ocular hypertension, central corneal thickness was significantly $(P<0.001)$ reduced by both latanoprost $(-14.95 \pm 5.04 \mu \mathrm{m})$ and travoprost $(-15.73 \pm 3.25 \mu \mathrm{m})$ after a mean follow-up of 17 months. ${ }^{36}$

The overall results from randomized controlled studies therefore show that latanoprost is as effective as travoprost. Further evidence is available from meta-analyses that will be discussed later in the review.

\section{Tafluprost}

Only two studies have so far been published comparing latanoprost with tafluprost. The first of these was a randomized double-blind Phase II trial comparing latanoprost with tafluprost treatment for 42 days in 38 patients with open-angle glaucoma, exfoliation glaucoma, or ocular hypertension. ${ }^{39}$ There was no significant difference between the treatments, with maximum IOP reduction occurring after 7 days and being maintained on day 42 and day 43. A subsequent randomized double-blind Phase III study was considerably larger, enrolling 533 patients with open-angle glaucoma or ocular hypertension. ${ }^{40}$ Treatment was given with latanoprost or tafluprost for 24 months. Both treatments substantially reduced IOP, with a $7.7 \mathrm{mmHg}$ decrease with latanoprost and $7.1 \mathrm{mmHg}$ decrease with tafluprost after 24 months. The effect of latanoprost was somewhat larger, but non-inferiority of tafluprost over all diurnal IOP measurements was shown with analysis of variance and almost reached with analysis of covariance (upper limits of the $95 \%$ CIs 1.38 and 1.52 , respectively). The non-inferiority limit was $1.5 \mathrm{mmHg}$. In this study, there were 18 discontinuations for lack of efficacy on tafluprost compared with only three on latanoprost.

Overall, the relatively restricted amount of data currently available suggests no clinically significant difference in efficacy between latanoprost and tafluprost, although more studies are required.

\section{Results of meta-analyses}

A number of recent meta-analyses of randomized controlled trials have compared latanoprost with bimatoprost and travoprost in patients with glaucoma or ocular hypertension (Table 1$){ }^{41-49}$ to date, only one meta-analysis has included a comparison with tafluprost (Table 1). ${ }^{50}$

One of the largest of these analyses was performed by Eyawo et al, in 2009, ${ }^{41}$ who assessed randomized single- or double-blind head-to-head comparisons of latanoprost, bimatoprost, and travoprost of at least 3 months' duration. Data were included from a total of 15 studies (up to 12 months' duration), five of which had more than two treatment arms. Thus, nine trials compared latanoprost and travoprost $(n=1,098)$, eight compared travoprost and bimatoprost $(n=714)$, and eight compared latanoprost and bimatoprost $(n=943)$. The IOP-lowering effect at study conclusion was expressed by the weighted mean difference across groups. This was $-0.24 \mathrm{mmHg}(95 \% \mathrm{CI}-0.87-0.38)$ for travoprost versus latanoprost and $0.73 \mathrm{mmHg}(95 \% \mathrm{CI} 0.10-1.37)$ for latanoprost versus bimatoprost. Response rates were also compared between studies that had similar definitions of response; three trials comparing latanoprost to bimatoprost found a pooled relative risk of 0.98 (95\% CI $0.76-1.26$, $P=0.87$ ) and two comparing travoprost to latanoprost found a pooled relative risk of 1.15 (95\% CI $0.99-1.33, P=0.07)$. A study specifically designed to identify the nonresponder rate during latanoprost treatment found that only 14 of 340 newly diagnosed patients failed to respond to latanoprost. ${ }^{51}$

Another large analysis was conducted in 2010 and involved 2,943 patients treated with latanoprost, bimatoprost, travoprost, or timolol in 18 studies. ${ }^{42}$ A mixed treatment comparison was used to assess the relative efficacy of the treatments in terms of absolute on-treatment IOP at 3 months. Latanoprost and bimatoprost produced significantly $(P<0.05)$ lower on-treatment IOP compared with timolol. There was no significant difference between latanoprost and bimatoprost. 
Table I Summary of meta-analyses of randomized controlled trials for the effect of latanoprost and other PG analogs on IOP in patients with glaucoma or ocular hypertension

\begin{tabular}{|c|c|c|c|c|c|c|}
\hline Study & PG analogs & $\begin{array}{l}\text { Other drugs } \\
\text { assessed }\end{array}$ & $\begin{array}{l}\text { Studies } \\
\text { (n) }\end{array}$ & $\begin{array}{l}\text { Patients } \\
\text { (n) }\end{array}$ & Duration & Primary efficacy variables \\
\hline $\begin{array}{l}\text { Cucherat } \\
\text { et } \mathrm{al}^{50}\end{array}$ & $\begin{array}{l}\text { LAT (BAK-preserved } \\
\text { and preservative-free), } \\
\text { BIM }^{f} \text { (BAK-preserved), } \\
\text { TRA (preserved with BAK, } \\
\text { polyquaternium-I or sofzia), } \\
\text { TAF (BAK-preserved) }\end{array}$ & None & 21 & $\begin{array}{l}\text { Not } \\
\text { reported }\end{array}$ & $\geq 2$ months & $\begin{array}{l}\text { Preservative-free LAT significantly } \\
\text { more effective than TAF regarding IOP } \\
\text { at } 3 \text { months. No significant difference } \\
\text { between other PG analogs. }\end{array}$ \\
\hline $\begin{array}{l}\text { Orme } \\
\text { et } \mathrm{al}^{42}\end{array}$ & LAT, BIM, TRA & TIM & 18 & 2,943 & 3 months & $\begin{array}{l}\text { No significant difference between LAT } \\
\text { and BIM in on-treatment IOP. LAT and } \\
\text { BIM significantly more effective than } \\
\text { TIM. No significant difference between } \\
\text { TRA and TIM. }\end{array}$ \\
\hline $\begin{array}{l}\text { Cheng } \\
\text { et } \mathrm{al}^{43}\end{array}$ & LAT, BIM, TRA & TIM & 9 & 1,090 & $\begin{array}{l}2 \text { weeks to } \\
3 \text { months }\end{array}$ & $\begin{array}{l}\text { No significant difference in IOP- } \\
\text { lowering effect from baseline between } \\
\text { LAT, BIM, TRA, and TIM. }\end{array}$ \\
\hline $\begin{array}{l}\text { Cheng } \\
\text { et } \mathrm{al}^{44}\end{array}$ & LAT, BIM & $\begin{array}{l}\text { TIM, DOR, } \\
\text { BRIM }\end{array}$ & 15 & 450 & $\begin{array}{l}3 \text { weeks to } \\
2 \text { months }\end{array}$ & $\begin{array}{l}\text { No significant difference between LAT } \\
\text { and BIM in IOP reduction from baseline } \\
\text { at peak, trough, and diurnal assessments. }\end{array}$ \\
\hline $\begin{array}{l}\text { Eyawo } \\
\text { et } \mathrm{al}^{41}\end{array}$ & LAT, BIM, TRA & None & 15 & 2,755 & $3-12$ months & $\begin{array}{l}\text { No significant differences in IOP- } \\
\text { lowering effects at study conclusion } \\
\text { between LAT, BIM, and TRA. }\end{array}$ \\
\hline $\begin{array}{l}\text { Aptel } \\
\text { et al }\left.\right|^{45}\end{array}$ & LAT, BIM, TRA & None & 8 & 1,610 & I-6 months & $\begin{array}{l}\text { Significantly greater change in IOP with } \\
\text { BIM than LAT at } 8 \text { am, noon, } 4 \text { pm, and } \\
8 \text { pm after } 3 \text { months. No significant } \\
\text { difference between LAT and TRA. }\end{array}$ \\
\hline $\begin{array}{l}\text { Cheng } \\
\text { and Wei }{ }^{46}\end{array}$ & LAT, BIM & None & 13 & 1,302 & I-6 months & $\begin{array}{l}\text { Percentage reduction in morning IOP } \\
\text { significantly greater with BIM than LAT } \\
\text { at } I, 3 \text {, and } 6 \text { months. }\end{array}$ \\
\hline $\begin{array}{l}\text { Stewart } \\
\text { et al }{ }^{48}\end{array}$ & LAT, BIM, TRA & $\begin{array}{l}\text { TIM, DOR, } \\
\text { BRIM }\end{array}$ & 11 & 386 & I-2 months & $\begin{array}{l}\text { No significant differences reported in } \\
\text { the publication between LAT, BIM, and } \\
\text { TRA in 24-hour IOP efficacy. }\end{array}$ \\
\hline $\begin{array}{l}\text { Denis } \\
\text { et } \mathrm{al}^{49}\end{array}$ & LAT, BIM, TRA & None & 9 & 1,318 & $\begin{array}{l}2 \text { weeks to } \\
12 \text { months }\end{array}$ & $\begin{array}{l}\text { No significant difference between LAT } \\
\text { and BIM or TRA in IOP levels at the } \\
\text { end of follow-up. }\end{array}$ \\
\hline $\begin{array}{l}\text { Van der } \\
\text { Valk et } \mathrm{al}^{47}\end{array}$ & LAT, BIM, TRA & $\begin{array}{l}\text { TIM, DOR, } \\
\text { BRIM, BET, } \\
\text { BRIN }\end{array}$ & 28 & $\begin{array}{l}6,953 \text { (trough) } \\
6,841 \text { (peak) }\end{array}$ & I-6 months & $\begin{array}{l}\text { No significant difference between LAT, } \\
\text { BIM, and TRA in IOP change from } \\
\text { baseline at I month. }\end{array}$ \\
\hline
\end{tabular}

Note: ${ }^{f} 0.01 \%$ and $0.03 \%$.

Abbreviations: BAK, benzalkonium chloride; BET, betaxolol; BIM, bimatoprost (0.03\%); BRIN, brinzolamide; BRIM, brimonidine; DOR, dorzolamide; IOP, intraocular pressure; LAT, latanoprost (0.005\%); PG, prostaglandin; TAF, tafluprost (0.0015\%); TIM, timolol; TRA, travoprost (0.004\%).

A somewhat smaller analysis in 1,090 patients showed no significant difference in the IOP-lowering effects from baseline of latanoprost, bimatoprost, travoprost, or timolol in studies ranging from 2 weeks to 3 months. ${ }^{43}$ The difference in absolute IOP reduction between PG analogs and timolol ranged from $0.4-1.6 \mathrm{mmHg}$ for the diurnal curve, $0.9-2.3 \mathrm{mmHg}$ for the peak, and 1.3-2.4 $\mathrm{mmHg}$ for the trough. For latanoprost, the relative IOP reduction was $31 \%$ (95\% CI 27\%-34\%) for the diurnal curve, 34\% (95\% CI $31 \%-37 \%$ ) for the peak, and $31 \%$ (95\% CI $28 \%-35 \%)$ for the trough. The corresponding values were $26 \%$ (95\% CI 21\%-30\%), 28\% (95\% CI 24\%-32\%), and $27 \%(95 \% \mathrm{CI} 23 \%-30 \%)$ for bimatoprost and $28 \%(95 \%$
CI $20 \%-36 \%$ ), $32 \%$ (95\% CI $31 \%-34 \%$ ), and $31 \%$ (95\% CI $29 \%-33 \%$ ) for travoprost, respectively.

Another analysis by Cheng et al in 450 patients with normal tension glaucoma reported no statistically significant differences between latanoprost and bimatoprost with regard to reductions in IOP at peak, trough, and diurnal assessments $(-20 \%$ at all assessments with latanoprost versus $21 \%, 18 \%$, and $17 \%$, respectively, with bimatoprost). ${ }^{44}$

The 24-hour IOP lowering efficacy, determined in one analysis of 386 patients, showed a statistically significant difference between monotherapy treatments with PG analogs, timolol, brimonidine, and dorzolamide $(P=0.026){ }^{48}$ 
As a class, the PG analogs were reported to be the most effective, with reductions of $24 \%$ with latanoprost, $27 \%$ with travoprost, and 29\% with bimatoprost. The mean reduction seen at night-time assessments was significantly lower than that at day-time assessments for latanoprost $(P=0.031)$ but not for the other PG analogs.

Two slightly older meta-analyses, each of which included more than 1,000 patients, also failed to report statistically significant differences in IOP-lowering efficacy between latanoprost and bimatoprost or travoprost. ${ }^{47,49}$ The only exception to this was a significantly higher adjusted favorable response rate (IOP $<18 \mathrm{mmHg}$ ) with bimatoprost and travoprost than with latanoprost (incidence rate ratio 1.17 ; 95\% CI 1.00-1.351, $P<0.040$ ) in one of the analyses. $^{49}$

In contrast to these previous meta-analyses, Aptel et $\mathrm{al}^{45}$ found that latanoprost was significantly less effective than bimatoprost, and equally as effective as travoprost, in reducing IOP after 3 months in an analysis of 1,610 patients. The IOP change from baseline was statistically significantly greater with bimatoprost than latanoprost at all time points assessed: 8 am (weighted mean $0.50 \mathrm{mmHg}$; 95\% CI 0.01-0.99, $P=0.05$ ), noon (weighted mean $1.17 \mathrm{mmHg}$; 95\% CI 0.68-1.66, $P<0.001$ ), 4 pm (weighted mean 0.78 $\mathrm{mmHg}$; 95\% CI 0.26-1.29, $P=0.003$ ), and 8 pm (weighted mean $0.67 \mathrm{mmHg}$; 95\% CI 0.02-1.32, $P=0.04$ ). Data for 8 pm were available from only three studies compared with data for the other time-points which were available from five studies. No significant heterogeneity was seen between studies.

Another meta-analysis published in the same year and in a similar number of patients reported significant advantages of bimatoprost over latanoprost on some, but not all, parameters. ${ }^{46}$ Bimatoprost resulted in statistically significantly greater reductions from baseline in morning (8 am to $10 \mathrm{am}$ ) IOP compared with latanoprost after 1, 3, and 6 months (weighted mean differences $2.59 \%, 2.41 \%$, and $5.60 \%$, respectively). In contrast, there were no statistically significant differences between the treatments in diurnal reduction in IOP after 1 and 3 months (no data available at 6 months) or in the proportion of patients achieving the target IOP ( $\leq 17 \mathrm{mmHg}$ ) after 1 or 6 months. At 3 months, more patients treated with bimatoprost reached target IOP (pooled rate difference $12 \% ; 95 \% \mathrm{CI} 4-21, P=0.004)$. However, the number of studies measuring diurnal IOP reduction and achievement of target IOP is small. Interestingly, in a post-hoc analysis excluding studies that were not industry-sponsored, the difference between bimatoprost and latanoprost in the reduction in morning IOP remained statistically significant only at 6 months. ${ }^{46}$

Finally, the most recent meta-analysis has included tafluprost in a comparison with latanoprost, including preservative-free latanoprost, and the other PG analogs. ${ }^{50}$ In contrast to the previous meta-analyses, which involved direct pairwise comparisons between treatments, this analysis used adjusted indirect comparisons in the absence of head-to-head trial data. Although the evidence from large double-blind randomized trials directly comparing the available treatments would clearly be stronger, it has been suggested that indirect comparisons are more appropriate than pairwise direct comparisons of a limited number of treatments as they allow comparison of all the options. ${ }^{50}$ A total of 21 trials of $\geq 2$ months' duration were included in the analysis; five trials comparing more than two treatments in a three-arm design were included as a total of ten entries, thus yielding 26 pairwise comparisons overall. Where no 3-month data were available, the data at 2-6 months were used, taking the longest period in case of multiple time points. The treatments compared were BAK-preserved latanoprost (12 trials), preservative-free latanoprost (one trial), BAKpreserved bimatoprost $0.03 \%$ (15 trials), BAK-preserved bimatoprost $0.01 \%$ (two trials), BAK-preserved travoprost (15 trials), travoprost preserved with polyquaternium-1 or sofZia (two trials), and BAK-preserved tafluprost (one trial). There were no statistically significant differences in mean IOP at 3 months between preservative-free latanoprost and polyquaternium-1-travoprost (weighted mean difference 0.47 ; 95\% CI $-0.58-1.51$ ), BAK bimatoprost $0.03 \%$ (weighted mean difference $0.49 ; 95 \% \mathrm{CI}-0.13-1.10$ ), BAK bimatoprost $0.01 \%$ (weighted mean difference $0.19 ; 95 \%$ $\mathrm{CI}-0.60-1.06$ ), BAK travoprost (weighted mean difference 0.27 ; $95 \% \mathrm{CI}-0.50-1.03$ ), or BAK latanoprost (weighted mean difference $0.40 ; 95 \% \mathrm{CI}-0.02$ to 0.82 ). However, preservative-free latanoprost was statistically significantly superior to BAK tafluprost (weighted mean difference -0.90; $95 \% \mathrm{CI}-1.52$ to -0.28 ). No data were available for sofZia travoprost.

Overall, the majority of meta-analyses have found no statistically significant differences between the efficacy of latanoprost and that of bimatoprost or travoprost. In a few cases, bimatoprost has shown significantly better efficacy than latanoprost in some parameters, but the numerical differences tend to be small and the clinical relevance unknown. The only meta-analysis that has so far included tafluprost reported it to be significantly less effective than preservativefree latanoprost. 


\section{Latanoprost versus other agents \\ Timolol}

Latanoprost is more effective than conventional treatment with the beta-blocker timolol $(0.5 \%)$ and has the added advantage of being required only once-daily, while beta-blockers are often applied twice daily. The benefits of latanoprost have been demonstrated in numerous clinical trials and meta-analyses.

One meta-analysis involving 829 patients with openangle glaucoma or ocular hypertension enrolled in three double-blind randomized studies reported that latanoprost reduced mean diurnal IOP by $7.7 \mathrm{mmHg}$ after 6 months, compared with $6.5 \mathrm{mmHg}$ with timolol. ${ }^{52}$ This difference of $1.2 \mathrm{mmHg}$ was statistically significant $(P<0.001)$. Morning IOP was reduced significantly $(P<0.001)$ more at 6 months than at 2 weeks in patients treated with latanoprost; no such increased efficacy was seen with timolol. In a subanalysis of 441 patients with ocular hypertension, mean diurnal IOP was reduced to a significantly greater extent with latanoprost than timolol $(1.1 \pm 0.2 \mathrm{mmHg} ; 95 \%$ CI $1.6-0.7, P<0.001) .{ }^{53}$ A reduction in diurnal IOP from baseline of $\geq 20 \%$ was achieved in $83 \%$ of patients treated with latanoprost and $62 \%$ treated with timolol.

Analogous findings were seen in another meta-analysis of eleven randomized controlled trials, ten of which were doubleblind, conducted in 1,256 patients with open-angle glaucoma or ocular hypertension. ${ }^{54}$ Both drugs significantly decreased IOP. However, the reductions were greater with latanoprost than with timolol for assessments performed at 1 week $(6.9 \mathrm{mmHg}$; $95 \%$ CI 0.4-13.4), 1 month (3.8 mmHg; 95\% CI 1.2-6.3), 3 months (5.0 mmHg; 95\% CI 2.8-7.3), 6 months (5.0 mmHg; 95\% CI 2.8-7.3), and 12 months (4.9 mmHg; 95\% CI -5.9-15.8). The differences were all statistically significant apart from that from the single 12-month study.

A recent randomized double-blind trial showed that latanoprost was at least as effective as timolol in 137 pediatric patients ( $\leq 18$ years old; mean age 8.8 years) with glaucoma. ${ }^{55}$ After 12 weeks, the mean reduction in IOP was $7.2 \mathrm{mmHg}$ with latanoprost and $5.7 \mathrm{mmHg}$ with timolol (difference $1.5 \mathrm{mmHg} ; 95 \% \mathrm{CI}-0.8-3.7)$. The responder rates were $60 \%$ with latanoprost and $52 \%$ with timolol.

\section{Dorzolamide}

Another conventional treatment option - the carbonic anhydrase inhibitor dorzolamide - is also significantly less effective than latanoprost. For example, a systematic review conducted in 2008 evaluated 1,722 glaucoma patients treated with latanoprost, dorzolamide, or brimonidine in eight randomized controlled trials. ${ }^{56}$ The mean reduction in IOP was statistically significantly larger with latanoprost than dorzolamide (weighted mean difference $-2.64 ; P<0.00001$ ).

\section{Brimonidine}

Superior efficacy of latanoprost has also been confirmed in comparisons with the $\alpha_{2}$-adrenergic agonist brimonidine. A meta-analysis of nine randomized controlled clinical trials in 2,152 patients with an IOP of $\geq 20 \mathrm{mmHg}$ observed a significantly greater reduction in IOP with latanoprost than brimonidine after 3 months ( 8.4 versus $6.5 \mathrm{mmHg} ; P=0.004)$ and 6 months $(8.0$ versus $6.2 \mathrm{mmHg} ; P=0.045) .{ }^{57} \mathrm{~A}$ more recent analysis included 1,784 patients with open-angle glaucoma, ocular hypertension, or normal-tension glaucoma enrolled in 14 randomized controlled trials of up to 12 months' duration. ${ }^{58}$ The overall reduction in IOP was significantly greater with latanoprost than brimonidine (weighted mean difference $=1.10 \mathrm{mmHg}$; 95\% CI 0.57-1.63).

\section{Combination therapies}

A wide range of treatment combinations with two or even three agents is used clinically in patients who do not respond to a single agent. One of the drugs more commonly given in combination is timolol; latanoprost has been used effectively with this agent ${ }^{59,60}$ as well as with others such as cholinergic agonists, ${ }^{61}$ dorzolamide, ${ }^{62}$ and brimonidine. ${ }^{62}$ A combination of latanoprost with $0.5 \%$ timolol was suggested to have better IOP-lowering efficacy than timolol combined with bimatoprost, dorzolamide, brinzolamide, or brimonidine, and comparable efficacy to a timolol-travoprost combination, in a recent meta-analysis of 41 randomized controlled trials in 5,261 patients with open-angle glaucoma or ocular hypertension. ${ }^{60}$ Combination of latanoprost and cholinergic agonists is usually not recommended. However, latanoprost given in combination with physostigmine has a mainly additive ocular hypotensive effect, and high doses of physostigmine, therefore, do not abolish the IOP-lowering effect of latanoprost. ${ }^{63}$

Latanoprost alone has also been compared with a variety of drug combinations. In a meta-analysis of 14 randomized controlled studies in 2,149 patients with elevated IOP, latanoprost was significantly more effective in reducing mean diurnal IOP at 3 months than combined timolol and dorzolamide in patients whose IOP was insufficiently controlled by timolol alone at baseline (weighted mean difference 3.12\%; 95\% CI 0.47-5.78). ${ }^{64}$ Latanoprost proved at least as effective as the combination treatment in patients not receiving timolol at baseline. 
Although combination treatments may have the benefit of improved efficacy in some cases, they also increase the risk of ocular adverse events. This risk appears to correlate with the number of treatments used. In an investigation of 630 patients receiving IOP-lowering medications, 305 were found to have an ocular surface disease index indicating mild ( $\mathrm{n}=134)$, moderate $(n=84)$, or severe $(n=87)$ symptoms. ${ }^{65}$ Those taking a single medication had a significantly lower mean index score (12.9 \pm 13.1$)$ than those taking two $(16.7 \pm 17.0 ; P=0.007)$ or three medications $(19.4 \pm 18.1 ; P=0.0001)$.

\section{Safety and tolerability}

A good safety and tolerability profile is essential in light of the long-term treatment required for patients with glaucoma or ocular hypertension. Latanoprost does not have any proven systemic effect but can cause ocular adverse events such as conjunctival hyperemia; pigmentation of the iris, periocular skin or eyelashes; hypertrichosis; and ocular surface effects or irritation.

Numerous individual clinical studies and meta-analyses have shown that latanoprost is better tolerated than bimatoprost or travoprost. ${ }^{25,29,31,33,41,42,45,46.50,66-69}$ Data currently available from two studies show that the safety and tolerability profile (including adverse events and drop discomfort) of latanoprost is comparable to that of tafluprost, although more information is required from further studies. ${ }^{39,40}$ However, the only available meta-analysis including tafluprost showed that the preservative-free formulation of latanoprost was better tolerated with regard to hyperemia. ${ }^{50}$

\section{Conjunctival hyperemia}

Conjunctival hyperemia has been associated with virtually all topical IOP-lowering medications including PG analogs, alpha-adrenergic agonists, beta-adrenergic antagonists, and carbonic anhydrase inhibitors. ${ }^{70}$ As well as representing a cosmetic problem for the patient, hyperemia may also compromise the outcome of filtration surgery. ${ }^{71}$ There are a number of different scales used in grading hyperemia as well as difficulties associated with comparing the results of studies that use different grading scales. Although it is possible to cross-calibrate such scales, the differences between them should always be borne in mind when comparing treatments. ${ }^{72}$ It is the most frequently reported side effect of the PG analogs and is commonly a cause of treatment discontinuation, ${ }^{66}$ although it is less common with latanoprost than with bimatoprost or travoprost.

A considerable amount of data has been collected in clinical studies. For example, a randomized double-blind crossover study in 28 healthy volunteers showed that latanoprost had significantly less hyperemia and/or change in hyperemia than bimatoprost or travoprost at hour 0 and/or $1 .{ }^{68}$ A large randomized controlled trial compared latanoprost, bimatoprost, and travoprost over 12 weeks in 411 patients with open-angle glaucoma or ocular hypertension. ${ }^{25}$ The incidence of hyperemia was $47.1 \%$ with latanoprost, $68.6 \%$ with bimatoprost, and 58.0\% with travoprost $(P=0.001$ for difference between latanoprost and bimatoprost). A greater proportion of hyperemia was observed at the end of the study in the bimatoprost (60.9\%) and travoprost (58.9\%) groups than in patients treated with latanoprost (46.5\%). Latanoprost was also associated with less hyperemia than bimatoprost in three other randomized, single- or double-blind studies in 232, 44 and 269 patients. ${ }^{29,31,33}$

A summary of meta-analyses of randomized controlled trials assessing the incidence of conjunctival hyperemia with latanoprost and other PG analogs in patients with glaucoma or ocular hypertension is shown in Table $2 .{ }^{41,42,45,46,50,66}$ One of these, published in 2009, was solely designed to assess the risk of conjunctival hyperemia with latanoprost versus other PG analogs. ${ }^{66}$ A total of 13 trials conducted between 1995 and 2007 including 2,222 patients (931 treated with latanoprost, 624 with bimatoprost, and 667 with travoprost) were included in the final analysis. The average period of follow-up was 4.1 months. Compared with latanoprost, there was a significantly higher risk of developing hyperemia with travoprost (odds ratio $0.51 ; P<0.0001 ; 95 \%$ CI $0.39-0.67$ ) and bimatoprost (odds ratio $0.32 ; P<0.0001 ; 95 \%$ CI $0.24-0.42$ ). No significant heterogeneity was found between the trials and there was no evidence of a publication bias. Sensitivity analyses showed that none of the included trials had an important impact on the global estimation of the odds ratio.

Other meta-analyses have investigated hyperemia in addition to analysis of effects on IOP. The results are consistent, with a significantly lower risk for developing hyperemia in patients treated with latanoprost. For example, six studies comparing latanoprost with travoprost, and five comparing latanoprost with bimatoprost, showed a significantly lower risk with latanoprost than travoprost (relative risk 5.71; $P \leq 0.001$ ) or bimatoprost (relative risk $1.59 ; P=0.04){ }^{41}$ Two other recent meta-analyses, both conducted in more than 1,000 patients, reported a significantly lower incidence with latanoprost than bimatoprost, with a relative risk of 0.59 $(P<0.001)$ in one case ${ }^{45}$ and a rate difference of $20 \%$ in the other. ${ }^{46}$ A particularly large analysis of 14,849 patients enrolled in 72 studies assessing 19 treatment regimens found that latanoprost monotherapy was associated with 
Table 2 Summary of meta-analyses of randomized controlled trials of latanoprost and other PG analogs in patients with glaucoma or ocular hypertension: occurrence of conjunctival hyperemia

\begin{tabular}{|c|c|c|}
\hline Study & Studies analyzed & Conjunctival hyperemia \\
\hline Cucherat et $\mathrm{al}^{50}$ & $\begin{array}{l}2 \text { I studies with LAT (BAK-preserved and preservative- } \\
\text { free), BIMf }{ }^{f} \text { BAK-preserved), TRA (preserved with BAK, } \\
\text { polyquaternium-I, or sofZia), or TAF (BAK-preserved) } \\
\text { over } \geq 2 \text { months. }\end{array}$ & 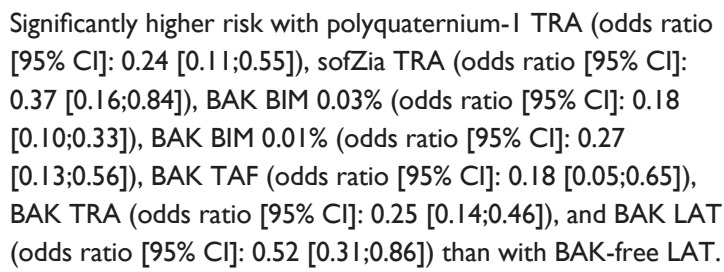 \\
\hline Orme et $\mathrm{al}^{42}$ & $\begin{array}{l}72 \text { studies of } 19 \text { different single or combination } \\
\text { treatment regimens in } 14,849 \text { patients. }\end{array}$ & $\begin{array}{l}\text { LAT monotherapy had a significantly }(P<0.05) \text { lower odds of } \\
\text { hyperemia-type events than TRA, BIM, TRA plus TIM, and BIM } \\
\text { plus TIM. }\end{array}$ \\
\hline Honrubia et $a^{66}$ & $\begin{array}{l}\text { Meta-analysis specifically designed to assess conjunctival } \\
\text { hyperemia. } 13 \text { studies in } 2,222 \text { patients treated for } 2 \text { weeks to } \\
9 \text { months compared LAT versus TRA ( } 5 \text { studies), LAT versus } \\
\text { BIM ( } 7 \text { studies), and LAT versus TRA versus BIM (I study). }\end{array}$ & $\begin{array}{l}\text { Significantly higher risk with TRA than LAT (odds ratio 0.5 I; } \\
P<0.000 \text { I; } 95 \% \mathrm{Cl} 0.39-0.67 \text { ) and with BIM than LAT (odds } \\
\text { ratio } 0.32 ; P<0.000 \mathrm{I} ; 95 \% \mathrm{Cl} 0.24-0.42 \text { ). }\end{array}$ \\
\hline Eyawo et $\mathrm{al}^{41}$ & $\begin{array}{l}\text { Out of I } 5 \text { studies in } 2,755 \text { patients treated for } 3-12 \text { months, } \\
6 \text { compared LAT and TRA, } 5 \text { compared LAT and BIM, } \\
\text { and I compared BIM and TRA. }\end{array}$ & $\begin{array}{l}\text { Significantly higher risk with TRA than LAT (relative risk } 5.7 \mathrm{I} \text {; } \\
P \leq 0.00 \mathrm{I} ; 95 \% \mathrm{CI} \text { I.8I-I8.02), with BIM than LAT (relative } \\
\text { risk I.59; } P=0.04 ; 95 \% \mathrm{Cl} \text { I.02-2.48), and with TRA than BIM } \\
\text { (relative risk } 0.82 ; P=0.02 ; 95 \% \mathrm{Cl} 0.69-0.97 \text { ). }\end{array}$ \\
\hline Aptel et $\mathrm{al}^{45}$ & $\begin{array}{l}8 \text { studies in } 1,610 \text { patients treated with LAT, BIM, } \\
\text { or TRA for } 1-6 \text { months. }\end{array}$ & $\begin{array}{l}\text { Significantly higher incidence with BIM than LAT (relative risk } \\
0.59 ; P<0.00 \text { I } 95 \% \mathrm{Cl} 0.50-0.69 \text { ) or TRA (relative risk } 0.84 \text {; } \\
P=0.05 ; 95 \% \mathrm{Cl} 0.70-1.00 \text { ). }\end{array}$ \\
\hline $\begin{array}{l}\text { Cheng and } \\
\text { Wei }^{46}\end{array}$ & $\begin{array}{l}\text { I } 3 \text { studies in I,302 patients treated with LAT or BIM } \\
\text { for I- } 6 \text { months. }\end{array}$ & $\begin{array}{l}\text { Significantly higher frequency with BIM than LAT } \\
\text { (rate difference } 20 \% ; 95 \% \mathrm{CI} \text { I5-24). }\end{array}$ \\
\hline Stewart et al ${ }^{48}$ & $\begin{array}{l}\text { I I studies in } 386 \text { patients treated with LAT, BIM, TRA, } \\
\text { or non-PG analogs for I-2 months. }\end{array}$ & $\begin{array}{l}\text { Significantly higher incidence with TRA }(23 \% ; P<0.00 \text { I }) \text { than any } \\
\text { other treatment. Incidence } 8 \% \text { with LAT and I } 7 \% \text { with BIM. }\end{array}$ \\
\hline
\end{tabular}

Note: ${ }^{f} 0.01 \%$ and $0.03 \%$.

Abbreviations: BAK, benzalkonium chloride; BIM, bimatoprost ( $0.03 \%)$; Cl, confidence interval; LAT, latanoprost ( $0.005 \%)$; PG, prostaglandin; TAF, tafluprost (0.00I5\%); TIM, timolol; TRA, travoprost (0.004\%).

significantly $(P<0.05)$ lower odds of hyperemia-type events than travoprost, bimatoprost, travoprost plus timolol, and bimatoprost plus timolol. ${ }^{42}$ The only meta-analysis to include tafluprost showed that the risk of hyperemia was significantly $(P<0.05)$ lower with preservative-free latanoprost than with BAK-preserved bimatoprost $0.03 \%$, BAK-preserved bimatoprost $0.01 \%$, BAK-preserved travoprost, BAK-preserved latanoprost, travoprost preserved with polyquaternium-1 or sofZia, and BAK-preserved tafluprost. ${ }^{50}$

Hyperemia is a significant contributor to treatment discontinuation with the PG analogs, especially as many patients fail to appreciate any benefits relating to symptoms during short-term treatment. A review of 300 patient charts found that hyperemia was the most common side effect with PG-analog treatment, and that it accounted for stopping or changing medication in $63 \%$ of patients in whom changes were made due to side effects. ${ }^{71}$ In order to determine the costs associated with stopping or switching treatment, data from 13,977 newly treated glaucoma patients were extracted from the HealthCore Integrated Research Database of the Glaucoma Adherence and Persistency Study. ${ }^{73}$ Of these, 8,743 were treated with PG-analog monotherapy $(5,726$ with latano- prost, 1,633 with bimatoprost, and 1,384 with travoprost). Overall, the per-patient cost of treating hyperemia-free patients was US\$73.67, compared with US\$140.02, in those who discontinued treatment due to hyperemia. The lowest per-patient costs were seen in the group given latanoprost; increased costs due to a hyperemia-induced change in treatment were US\$5.92 with bimatoprost and US\$5.43 with travoprost.

\section{Iris pigmentation}

This well recognized side effect of PG analogs is irreversible and is seen markedly more often in green-brown and yellowbrown eyes than in blue-grey or brown eyes. ${ }^{22}$ The incidence is difficult to compare considering the wide range of eye colors, but there do not appear to be any marked differences between latanoprost and other PG analogs.

There is no evidence that an increase in pigmentation increases the risk of ocular or cutaneous melanoma with latanoprost. In order to assess this, a recent study reviewed two safety databases: one included all latanoprost $(n=24)$ and fixed-combination latanoprost/timolol $(n=16)$ clinical trials conducted between 1992 and 2007; 
and the other included all spontaneous global safety reports (not occurring in clinical trials) over 13 years for latanoprost and 9 years for latanoprost/timolol. ${ }^{74}$ There were three cases of cutaneous melanoma and none of ocular melanoma in the 12,880 patients in clinical trials. In the global safety database, which comprised 19,940 cases, there were eleven reports of ocular melanoma and six of cutaneous melanomas. A possible association with latanoprost was excluded for all but three ocular and one periorbital case. The potential mechanism of action by which prostaglandins increase iris pigmentation is thought to be due to stimulation of melanin synthesis via induction of tyrosinase transcription without an increase in mitotic activity. ${ }^{75}$

\section{Hypertrichosis}

Hypertrichosis refers to an increase in the length, thickness, and/or number of eyelashes. Although this can be desirable from a cosmetic point of view in some patients, unilateral occurrence can be unwanted. It can also influence drop instillation.

The incidence is reported to be higher with bimatoprost and travoprost than with latanoprost in some studies. In the large study by Parrish et al, ${ }^{25}$ no patients in the latanoprost group had hypertrichosis whilst it occurred in $2.9 \%$ in the bimatoprost group and $0.7 \%$ in the travoprost group. A lower incidence was also reported with latanoprost than bimatoprost ( $4.4 \%$ versus $12.6 \% ; P=0.026$ ) in the study by Gandolfi et al. ${ }^{29}$

\section{Periocular skin pigmentation}

This is a relatively rare side effect of the PG analogs and is reversible upon treatment discontinuation. The incidence has been reported to be higher with bimatoprost (2.9\%) and travoprost $(2.9 \%)$ than with latanoprost $(1.5 \%)$ in one study by Parrish et al..$^{25}$

\section{Ocular surface problems and irritation}

These include eye irritation, dry eye, itching, blurred vision, burning, discharge, allergy, and blepharitis, and these side effects occur at a similar incidence with all PG analogs. Many of these problems may be preservative related and, thus, may be reduced by the development of preservativefree product.

\section{Other local events}

Less common events seen with PG analogs include iris cysts, cystoid macular edema, anterior uveitis, reactivation of herpes simplex keratitis, and deepening of the upper eyelid sulcus. $^{76,77}$

\section{Systemic adverse events}

Systemic adverse events occurring via nasopharyngeal mucosal absorption of PG analogs are extremely infrequent due to their rapid elimination half-life. ${ }^{78}$ PGs do contract human airway muscles, but this seems to be mainly mediated by thromboxane receptors. ${ }^{79}$ Also, a randomized doubleblind cross-over study in 24 glaucoma patients with stable asthma exposed to 6 days of latanoprost treatment followed by a 2-week washout showed no significant effects on peak expiratory flow, asthma symptoms, or requirement for asthma medications ${ }^{78}$ Similarly, there was no evidence of any adverse cardiovascular or respiratory effects with latanoprost in a randomized controlled study specifically designed to assess these parameters. ${ }^{80}$ Forty newly-diagnosed glaucoma patients were treated with latanoprost $0.005 \%$ or betaxolol $0.25 \%$ for 3 months. At the end of the study, there were no significant changes in cardiovascular or spirometric measurements in the latanoprost group.

A recent study of pediatric patients $(<3$ years, $3-<12$ years, or $12-<18$ years) receiving adult latanoprost solution $0.005 \%$ once daily for $\geq 2$ weeks resulted in no discontinuations or dose reductions due to adverse events. ${ }^{15}$ The findings suggest that the adult dose of latanoprost has an adequate safety margin for systemic adverse effects in pediatric patients.

\section{Long-term studies}

Good long-term safety and tolerability is vitally important for drugs given for prolonged conditions such as glaucoma. For this reason, three long-term studies have assessed the safety and tolerability of latanoprost treatment over periods of 5 years. ${ }^{22-24}$

The first of these was conducted by Alm et al in 1984 and focused on the development and progression of iris pigmentation. ${ }^{22}$ Five hundred and nineteen patients with primary open-angle or exfoliation glaucoma enrolled in a 3-year open-label multinational uncontrolled prospective trial. Of these, 380 (approximately $89 \%$ of whom had an eye color known to be susceptible to color change) entered a subsequent 2-year extension phase. High-resolution color photographs of irises were taken at baseline and at 14 subsequent visits, and were assessed for change in iris pigmentation compared with baseline. Intraocular pressures and adverse events were also recorded. Overall, 127 patients (33.4\%) developed increased iris pigmentation in one or both eyes after 5 years. 
At baseline, abnormalities of the optic nerve head and disorders of the iris were slightly, but not significantly, more common in those who developed increased iris pigmentation, but retinal damage was slightly, but not significantly, less common in patients who developed increased iris pigmentation. All patients with increased iris pigmentation developed the condition by month 36 . Regression analysis of photographic ranking versus chronological order showed that there was increased progression over the first 3 post-baseline years and stability over the final 2 years. Almost all patients (92.6\%) reported a vision-related adverse event during the study - most commonly visual field defect, eye irritation, cataract, and eye abnormality. The incidences were between $30 \%$ and $40 \%$, and the majority were mild in intensity.

The second open-label study was larger and more wideranging, involving a total of 5,854 patients on IOP-reducing therapy other than latanoprost who required a change in therapy. ${ }^{23}$ Patients were randomly assigned (2:1, respectively) to latanoprost $(n=3,936)$ or to any other commercially available medication $(n=1,918)$. Of those initially randomized to latanoprost, 2,707 (68.8\%) completed the study and 4,638 $(79.2 \%)$ received at least one dose of latanoprost. The patients were examined at baseline and every 6 months for 5 years. The 5-year incidence of macular edema, iritis/uveitis, and corneal erosions was low $(\leq 2.72 \%)$ and was similar for patients treated with latanoprost and those treated with other medication. Kaplan-Meier estimates indicated a low risk $(\leq 3.17 \%)$ for each event at 5 years. Treatment discontinuation over 5 years due to macular edema, iritis/uveitis, corneal erosions, iris pigmentation, and asthma/chronic obstructive pulmonary disease occurred in 197/5,854 (0.3\%) patients. The rates were similar with latanoprost and with other medication. Discontinuation due to asthma/chronic obstructive pulmonary disease was more common with other medication than with latanoprost. Amongst patients who had ever been treated with latanoprost, investigators judged that $12.4 \%$ had increased iris pigmentation, $40.3 \%$ had eyelash changes, and $7.8 \%$ had increased pigmentation of the periorbital skin, although fewer patients considered that they had increased iris pigmentation $(8.2 \%)$ or eyelash changes $(28.7 \%)$.

The final one of these studies, also conducted by Alm et al, assessed a fixed combination of latanoprost and timolol. ${ }^{24}$ Nine hundred and eighty-two patients with openangle glaucoma or ocular hypertension were included in this open multination study and were assessed at baseline and 12 , 36 , and 60 months. Increased iris pigmentation incidence was compared with a historical control in a similarly designed latanoprost study. Amongst 828/974 treated patients with assessable iris photographs, 233 (28.1\%) developed increased iris pigmentation compared with $127 / 380$ (33.4\%) in the historic controls. Patents with mixed eye colors had a greater susceptibility to increased iris pigmentation $(85.8 \%$ in both studies). Most cases of iris pigmentation in this study were only mild. Eyelash changes were seen in $58.1 \%$ of patients and darkening of the eyelids in 5\%-6\%.

In conclusion, these large long-term studies indicate that latanoprost is safe and well tolerated during treatment over 5 years.

\section{Compliance and persistence}

In common with other insidious but symptomless conditions such as hypertension and dyslipidemia, compliance in glaucoma patients represents a real clinical challenge. Quigley proposed that improving compliance would be the equivalent of a second drop of medication. ${ }^{81}$ A systematic review of treatment with glaucoma medication in the US recently demonstrated how poor compliance is; prescription records suggested sufficient medication was only dispensed for around $56 \%$ of the treatment days during the first year of treatment. ${ }^{82} \mathrm{~A}$ recent comprehensive systematic review identified 58 studies of glaucoma eye-drop compliance and persistence, but concluded that compliance remains a problem for existing ocular hypotensive users, and that both compliance and persistence are problems for newly treated patients. ${ }^{82}$ The extent of the persistence issue was identified in a study of 167,907 patients receiving long-term treatment with statins, bisphosphonates, oral diabetics, angiotensin receptor antagonists, and overactive bladder medications. Persistence rates were lower for prostaglandin eye drops than for any other medication with the exception of those for overactive bladder. ${ }^{83}$ Among a population of 2,440 newly diagnosed glaucoma patients, $23 \%$ did not fill a prescription for their medication during the 12 months after their first prescription. ${ }^{84}$ As is the case in other therapeutic domains, multiple drug administration diminishes compliance and persistence ${ }^{85}$ Clearly, even with modern drugs such as the prostaglandin analogs, compliance and persistence remains a significant problem in the effective treatment of glaucoma.

Although the early symptoms of glaucoma do not appear to be particularly troublesome to patients, ${ }^{86}$ vision-related quality of life is diminished by the side effects of glaucoma therapy ${ }^{87}$ although treatments such as latanoprost, timolol, and their combination treatments may be better in this respect. ${ }^{45,88}$ Local adverse reactions are the most common cause of poor compliance ${ }^{86,87}$ and the second most common reason for switching medication after lack of efficacy. ${ }^{116}$ 
The comparative persistence and compliance to prescribed treatments has been well studied for latanoprost predominantly in retrospective observational studies but also in prospective studies. The results of the great majority of these studies (summarized in Table 3) show that treatment compliance and persistence are better with latanoprost eye drops than with other medications. ${ }^{105,108-110,112,113,115-118}$ However, this finding is not unequivocal, with two studies finding either an equivocal advantage or no advantage for latanoprost in comparison with other glaucoma treatments. ${ }^{114,120}$

Compliance remains a problem in the treatment of glaucoma and this problem is far from solved; however, the great weight of evidence suggests that latanoprost has an advantage in this area compared with other glaucoma treatments.

\section{Use of preservatives}

Preservatives are commonly used in ophthalmic preparations but can have adverse effects on the ocular surface, resulting in symptoms such as hyperemia, tearing, burning, irritation, itching, dryness, blurred vision, fluctuating visual acuity, pain, and decrease in vision. ${ }^{4,89,90}$ Even at very low concentrations, preservatives are cytotoxic for conjunctival cells and cause inflammation, apoptosis, and free radical production. ${ }^{91}$ Impairment of the ocular surface also increases with age; tear film thickness decreases, whilst there is an increase in tear evaporation rate, prevalence of meibomian dysfunction, and dry eye. ${ }^{92-95}$ This is particularly important as the incidence of glaucoma also increases with age, and so the patients' eyes are particularly sensitive to further damage.

As glaucoma requires lifetime treatment, a large proportion of patients receive multiple therapies over time. ${ }^{2}$ The Ocular Hypertension Treatment Study, carried out in 1,636 patients with no evidence of glaucomatous damage, showed that approximately $40 \%$ of patients initially diagnosed with ocular hypertension were using two drugs after 5 years, while $9 \%$ used three or more drugs. Such a combination of several eye drops is likely to increase the cumulative dose of preservatives. ${ }^{96}$

A number of studies have demonstrated that products without preservatives are more likely to be better tolerated and, therefore, improve compliance and quality of life, and possibly even efficacy. ${ }^{97-99}$ For example, 4,107 patients with glaucoma were treated with preserved eye drops (84\%), preservativefree eye drops $(13 \%)$, or a combination of the two $(3 \%){ }^{97}$ All symptoms were significantly $(P<0.001)$ more prevalent with preservative eye drops than preservative-free eye drops. This included discomfort upon instillation (43\% versus $17 \%$ ), burning/stinging ( $40 \%$ versus $22 \%$ ), foreign body sensation
( $31 \%$ versus $14 \%$ ), dry eye sensation ( $23 \%$ versus $14 \%$ ), tearing $(21 \%$ versus $14 \%)$, and eyelid itching (18\% versus $10 \%)$. The prevalence of signs and symptoms was dose dependent, increasing with the number of preservative eye drops. In a multinational study in 9,658 patients using preservative or preservative-free beta-blocking eye drops, a total of $74 \%$ used preservative eye drops, $12 \%$ used preservative-free eye drops, $10 \%$ used a combination, and $4 \%$ used an unknown type. ${ }^{97}$ Each symptom and all palpebral, conjunctival, and corneal signs were significantly more frequent $(P<0.0001)$ in the preservative group than in the preservative-free group. Upon a second evaluation, there was a significant decrease $(P<0.0001)$ in all ocular symptoms and signs in patients in whom the dose of preserved eye drops was diminished or was swapped to preservative-free drops (Figure 1).

\section{Development of preservative-free latanoprost eye drops}

The original latanoprost formulation contains the preservative BAK, and was required to be stored in the refrigerator to prevent degeneration (although recent advice permits storage at room temperature). In order to improve the ocular side-effect profile, a preservative-free unidose formulation of latanoprost (Monoprost ${ }^{\circledR}$; Laboratioires Thea, Clermont Ferrand, Germany) has recently been developed and approved in Europe. The pharmaceutical formulation includes Protriaxin ${ }^{\circledR}$ (Laboratioires Thea) - a complex of polymers including carbomer (widely used in artificial tears and other ophthalmic and medical preparations) with benign safety profiles. ${ }^{100}$ As well as ensuring the stability of the active ingredient at room temperature, the stability polymer complex also prevents adsorption of latanoprost onto the plastic surfaces of the delivery system, and provides $\mathrm{pH}$ stability and an appropriate viscosity to the drops.

Initial studies in an animal model showed that a preservative-free latanoprost formulation was as effective and was better tolerated than a formulation containing BAK. ${ }^{101}$ Both formulations were well tolerated, but the incidence of conjunctival hyperemia was reduced by $42 \%$ with the BAKfree latanoprost formulation. Subsequent studies in humans confirmed these findings.

A Phase III noninferiority randomized investigatormasked two-parallel-group study of Monoprost ${ }^{\circledR}$ versus reference preservative-containing drug formulations in 402 patients with open-angle glaucoma or ocular hypertension treated over a period of 3 months has been reported. ${ }^{102}$ The results showed that Monoprost ${ }^{\mathbb{B}}$ was noninferior for IOPlowering efficacy, with an IOP decrease of 8.6 and $9 \mathrm{mmHg}$ in the Monoprost ${ }^{\circledR}$ and control groups, respectively, without 


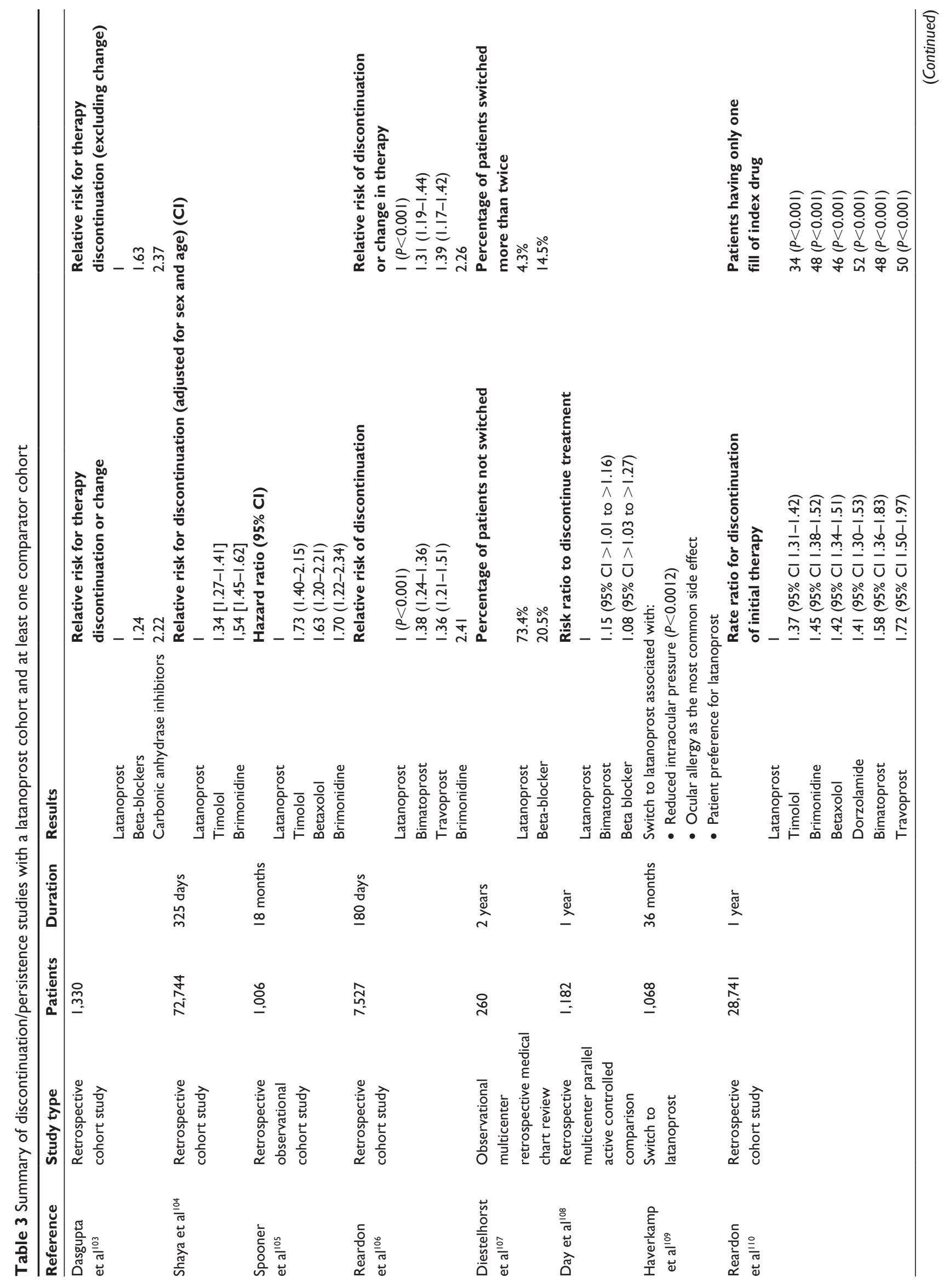




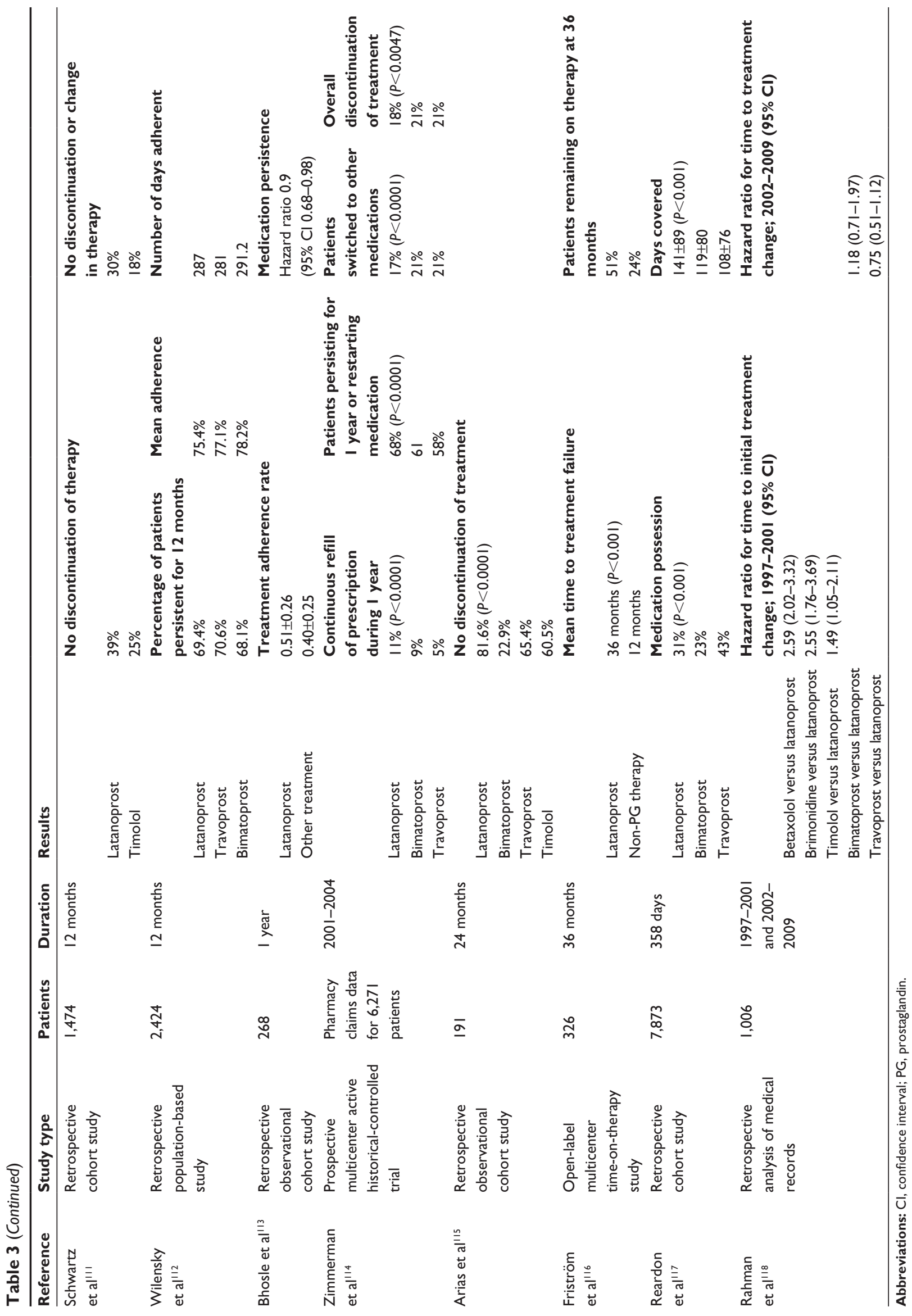




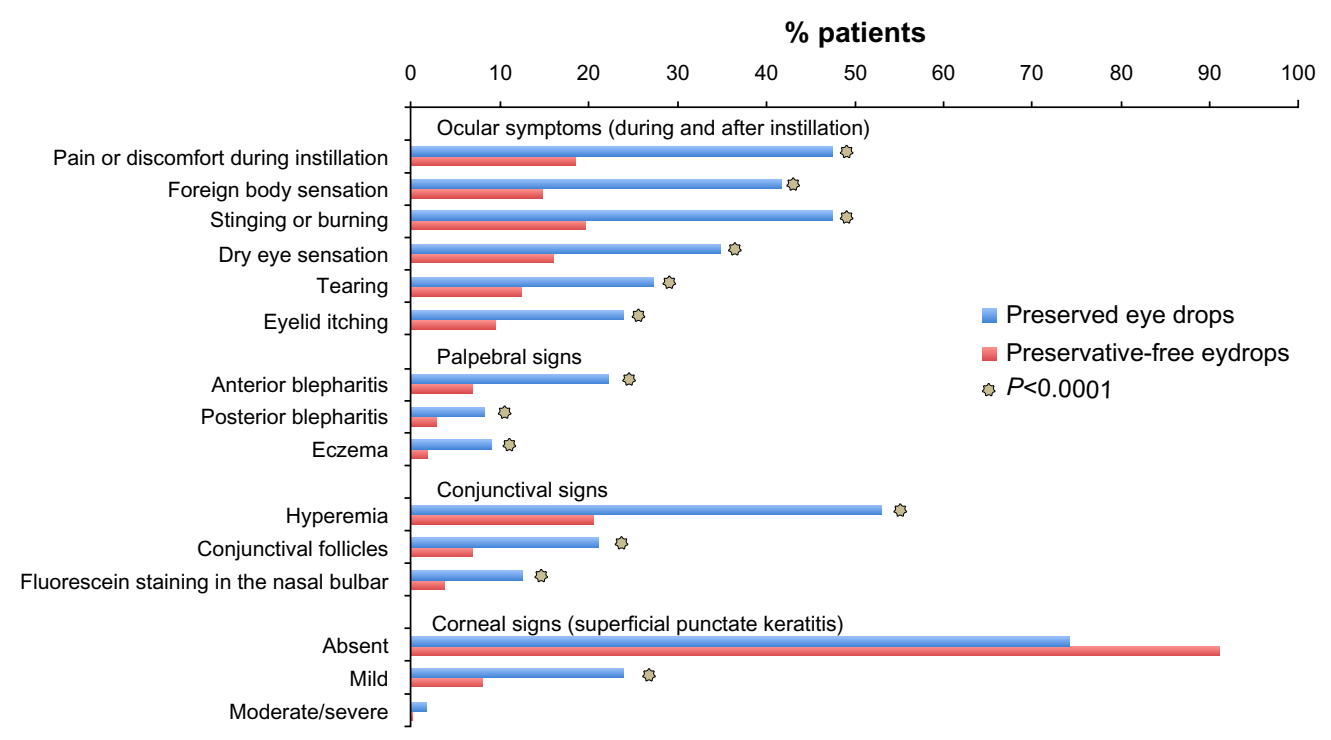

Figure I Ocular symptoms and signs with preserved and preservative-free glaucoma medications.

Notes: Frequency of signs and functional symptoms at visit I and visit 2 after switch from preserved to preservative-free eye drops or decrease of the number of preserved eye drops. Republished with permission of Wichtig Editore Srl, from Eur J Ophthalmol, Ocular symptoms and signs with preserved and preservative-free glaucoma medications, Jaenen N, Baudouin C, Pouliquen P, Manni G, Figueiredo A, Zeyen T, volume 17, 2007; ${ }^{77}$ permission conveyed through Copyright Clearance Center, Inc.

statistically significant difference. ${ }^{103}$ Conjunctival hyperemia was less frequent and less severe in the Monoprost ${ }^{\circledR}$ group, with a statistically significant lower incidence apparent in the worse eye at day $42(20.2 \%$ versus $30.6 \%, P=0.003)$ and day $84(21.4 \%$ versus $29.1 \%, P=0.019)$.

This study was also included into a meta-analysis, ${ }^{50}$ together with all previous randomized clinical trials of at least 2 months' duration, investigating any PG analog (with or without a preservative) compared to one another as monotherapy. Twenty-one relevant randomized controlled trials of head-to-head comparison between PG analogs, corresponding in 26 pairwise comparisons published before December 2011, were extracted by systematic review of Medline, Cochrane, and Embase databases to be included in a meta-analysis. The results showed no statistically significant differences in mean IOP at 3 months between Monoprost ${ }^{\mathbb{R}}$ and most other PG analogs, with the exception of BAKtafluprost, which was found to be statistically significantly inferior to Monoprost ${ }^{\circledR}$ with respect to this parameter. The risk of hyperemia was statistically significantly lower with Monoprost ${ }^{\circledR}$ than all other PG analogs.

\section{Conclusion}

Latanoprost has been extensively studied in the treatment of raised IOP, and the data presented in Tables 1 and 2 clearly attest to its efficacy. Latanoprost is at least as effective as other therapies in terms of the key efficacy parameter: IOP reduction. Moreover, since this agent has formed part of the glaucoma armamentarium for more than 15 years, practitioners can call upon considerable clinical experience with this agent.

Nevertheless, proven efficacy is of little value if side effects cause poor compliance and persistence with therapy. Compliance and persistence have been, and remain, significant problems for the treatment of glaucoma. The latest iteration of the European Glaucoma Society guidelines state:

While meta-analyses focus on IOP reduction, other aspects like patient characteristics, quality of life, side effects, convenience/compliance and cost-effectiveness should be taken into consideration in making a drug therapy choice particularly when IOP differences between the compounds are small. ${ }^{4}$

Latanoprost eye drops are not associated with systemic side effects. Local adverse effects may be troublesome in a proportion of patients, but its efficacy-tolerability relationship can be considered the best in its class. Specific studies strongly suggest that compliance and persistence with latanoprost is superior to that with other glaucoma treatments.

The disadvantages of preservatives in topical ocular therapies have been underestimated until recently. Fortunately, the problems such preservatives cause have now been recognized, and manufacturers of these therapies have responded with the development of ingenious formulations that avoid preservatives but maintain the sterility and other necessary properties of the preparation. Latanoprost is intended to be a chronic or lifetime treatment, so its availability in convenient preservative-free formulations is to be much welcomed. 
Overall, latanoprost is an effective and well-tolerated treatment for raised IOP. The superior compliance and persistence of patients using latanoprost, as well as the availability of a preservative-free formulation, mean it should be considered as an option for all glaucoma patients.

\section{Acknowledgments}

Dr JF Stolz provided assistance with the preparation of the manuscript; this assistance was reimbursed by Laboratoires Thea.

\section{Disclosure}

Prof A Alm has received remuneration from Laboratoires Thea. Dr JF Stolz assisted in the preparation of the manuscript. This work was reimbursed by Laboratoires Thea. The author reports no other conflicts of interest in this work.

\section{References}

1. Heijl A, Leske MC, Bengtsson B, et al. Reduction of intraocular pressure and glaucoma progression: results from the Early Manifest Glaucoma Trial. Arch Ophthalmol. 2002;120:1268-1279.

2. Kass MA, Heuer DK, Higginbotham EJ, et al. The Ocular Hypertension Treatment Study: a randomized trial determines that topical ocular hypotensive medication delays or prevents the onset of primary openangle glaucoma. Arch Ophthalmol. 2002;120:701-713.

3. Toris CB, Gabelt BT, Kaufman PL. Update on the mechanism of action of topical prostaglandins for intraocular pressure reduction. Surv Ophthalmol. 2008;53 Supp11:S107-S120.

4. European Glaucoma Society. Terminology and Guidelines for Glaucoma. 3rd ed. Savona: Dogma; 2008.

5. Von Euler US. Über die spezifische blutdrucksenkende Substanz des menschlichen Prostata- und Samenblasensekrets. Wien Klin Wochenschr. 1935;14:1182-1183. Available from: http://link.springer. com/article/10.1007\%2FBF01778029.

6. Prostanoids - prostaglandins, prostacyclins and thromboxanes: Chemistry and Biology [webpage on the Internet]. Boulder, IL: AOCS Lipid Library [updated January 7, 2014]. Available from: http://lipidlibrary. aocs.org/lipids/eicprost/index.htm. Accessed July 25, 2013.

7. Perkins ES. Prostaglandins and the eye. Adv Ophthalmol. 1975; 29:2-21.

8. Bito LZ, Baroody RA. The ocular pharmacokinetics of eicosanoids and their derivatives. 1. Comparison of ocular eicosanoid penetration and distribution following the topical application of PGF2a, PGF2a-1-methyl ester, and PGF2a-1-isopropyl ester. Exp Eye Res. 1987;44:217-226.

9. Bito LZ, Stjernschantz J, Resul B, Miranda OC, Basu S. The ocular effects of prostaglandins and the therapeutic potential of a new PGF2 alpha analog, PhXA41 (latanoprost), for glaucoma management. J Lipid Mediat. 1993;6:535-543.

10. Villumsen J, Alm A. Prostaglandin F2 alpha-isopropylester eye drops: effects in normal human eyes. Br J Ophthalmol. 1989;73:419-426.

11. Stjernschantz JW. From PGF(2alpha)-isopropyl ester to latanoprost: a review of the development of xalatan: the Proctor Lecture. Invest Ophthalmol Vis Sci. 2001;42:1134-1145.

12. Ota T, Aihara M, Narumiya S, Araie M. The effects of prostaglandin analogues on IOP in prostanoid FP-receptor-deficient mice. Invest Ophthalmol Vis Sci. 2005;46:4159-4163.

13. Ota T, Aihara M, Saeki T, Narumiya S, Araie M. The effects of prostaglandin analogues on prostanoid EP1, EP2, and EP3 receptor-deficient mice. Invest Ophthalmol Vis Sci. 2006;47:3395-3399.

14. Sjöquist B, Stjernschantz J. Ocular and systemic pharmacokinetics of latanoprost in humans. Surv Ophthalmol. 2002;47 Suppl 1:S6-S12.
15. Raber S, Courtney R, Maeda-Chubachi T, et al. Latanoprost systemic exposure in pediatric and adult patients with glaucoma: a phase 1, open-label study. Ophthalmology. 2011;118:2022-2027.

16. Camras CB, Alm A. Initial clinical studies with prostaglandins and their analogues. Surv Ophthalmol. 1997;41 Supp1 2:S61-S68.

17. Digiuni M, Fogagnolo P, Rossetti L. A review of the use of latanoprost for glaucoma since its launch. Expert Opinion. 2012;13:723-745.

18. Alm A, Camras CB, Watson PG. Phase III latanoprost studies in Scandinavia, the United Kingdom and the United States. Surv Ophthalmol. 1997;41 Suppl 2:S105-S110.

19. Johnstone MA, Albert DM. Prostaglandin-induced hair growth. Surv Ophthalmol. 2002;Supp1 1:S185-S202.

20. Hedman K, Watson PG, Alm A. The effect of latanoprost on intraocular pressure during 2 years of treatment. Surv Ophthalmol. 2002;47 Suppl 1: S65-S76.

21. Alm A, Widengård I. Latanoprost: experience of 2-year treatment in Scandinavia. Acta Ophthalmol Scand. 2000;78:71-76.

22. Alm A, Schoenfelder J, McDermott J. A 5-year, multicenter, openlabel, safety study of adjunctive latanoprost therapy for glaucoma. Arch Ophthalmol. 2004;122:957-965.

23. Goldberg I, Li XY, Selaru P, Paggiarino D. A 5-year, randomized, open-label safety study of latanoprost and usual care in patients with open-angle glaucoma or ocular hypertension. Eur J Ophthalmol. 2008;18:408-416.

24. Alm A, Grunden JW, Kwok KK. Five-year, multicenter safety study of fixed-combination latanoprost/timolol (Xalacom) for open-angle glaucoma and ocular hypertension. J Glaucoma. 2011;20:215-222.

25. Parrish RK, Palmberg P, Sheu WP; XLT Study Group. A comparison of latanoprost, bimatoprost, and travoprost in patients with elevated intraocular pressure: a 12-week, randomized, masked-evaluator multicenter study. Am J Ophthalmol. 2003;135:688-703.

26. Yildirim N, Sahin A, Gultekin S. The effect of latanoprost, bimatoprost, and travoprost on circadian variation of intraocular pressure in patients with open-angle glaucoma. J Glaucoma. 2008;17:36-39.

27. Orzalesi N, Rossetti L, Bottoli A, Fogagnolo P. Comparison of the effects of latanoprost, travoprost, and bimatoprost on circadian intraocular pressure in patients with glaucoma or ocular hypertension. Ophthalmology. 2006;113:239-246.

28. How AC, Kumar RS, Chen YM, et al. A randomised crossover study comparing bimatoprost and latanoprost in subjects with primary angle closure glaucoma. Br J Ophthalmol. 2009;93:782-786.

29. Gandolfi S, Simmons ST, Sturm R, Chen K, VanDenburgh AM; Bimatoprost Study Group 3. Three-month comparison of bimatoprost and latanoprost in patients with glaucoma and ocular hypertension. $A d v$ Ther. 2001;18:110-121.

30. DuBiner H, Cooke D, Dirks M, Stewart WC, VanDenburgh AM, Felix C. Efficacy and safety of bimatoprost in patients with elevated intraocular pressure: a 30-day comparison with latanoprost. Surv Ophthalmol. 2001;45 Suppl 4:S353-S360.

31. Konstas AG, Katsimbris JM, Lallos N, Boukaras GP, Jenkins JN, Stewart WC. Latanoprost $0.005 \%$ versus bimatoprost $0.03 \%$ in primary open-angle glaucoma patients. Ophthalmology. 2005;112: 262-266.

32. Dirks MS, Noecker RJ, Earl M, Roh S, Silverstein SM, Williams RD. A 3-month clinical trial comparing the IOP-lowering efficacy of bimatoprost and latanoprost in patients with normal-tension glaucoma. Adv Ther. 2006;23:385-394.

33. Noecker RS, Dirks MS, Choplin NT, Bernstein P, Batoosingh AL, Whitcup SM; Bimatoprost/Latanoprost Study Group. Bimatoprost/ Latanoprost Study Group. A six-month randomized clinical trial comparing the intraocular pressure-lowering efficacy of bimatoprost and latanoprost inpatients with ocular hypertension or glaucoma. Am J Ophthalmol. 2003;135:55-63.

34. Patwardhan AA, Khan M, Mollan SP, Haigh P. The importance of central corneal thickness measurements and decision making in general ophthalmology clinics: a masked observational study. BMC Ophthalmology. $2008 ; 8: 1$. 
35. Herndon LW, Weizer JS, Stinnett SS. Central corneal thickness as a risk factor for advanced glaucoma damage. Arch Ophthalmol. 2004;122:17-21.

36. Zhong Y, Shen X, Yu J, Tan H, Cheng Y. The comparison of the effects of latanoprost, travoprost, and bimatoprost on central corneal thickness. Cornea. 2011;30:861-864

37. Camras CB, Toris CB, Sjoquist B, et al. Detection of the free acid of bimatoprost in aqueous humor samples from human eyes treated with bimatoprost before cataract surgery. Ophthalmology. 2004;111: 2193-2198.

38. Maul E, Carrasco FG, Costa VP, et al. A 6-week, multicenter, randomized, double-masked, parallel-group study comparing travoprost $0.004 \%$ to latanoprost $0.005 \%$ followed by 6 -week, open-label treatment with travoprost 0.004\%. Clin Ther. 2007;29:1915-1923.

39. Traverso CE, Ropo A, Papadia M, Uusitalo H. A phase II study on the duration and stability of the intraocular pressure-lowering effect and tolerability of tafluprost compared with latanoprost. J Ocul Pharmacol Ther. 2010;26:97-104.

40. Uusitalo H, Pillunat LE, Ropo A. Phase III Study Investigators. Efficacy and safety of tafluprost $0.0015 \%$ versus latanoprost $0.005 \%$ eye drops in open-angle glaucoma and ocular hypertension: 24-month results of a randomized, double-masked phase III study. Acta Ophthalmol. 2010;88:12-19.

41. Eyawo O, Nachega J, Lefebvre P, et al. Efficacy and safety of prostaglandin analogues in patients with predominantly primary open-angle glaucoma or ocular hypertension: a meta-analysis. Clin Ophthalmol. 2009;3:447-456.

42. Orme M, Collins S, Dakin H, Kelly S, Loftus J. Mixed treatment comparison and meta-regression of the efficacy and safety of prostaglandin analogues and comparators for primary open-angle glaucoma and ocular hypertension. Curr Med Res Opin. 2010;26:511-528.

43. Cheng JW, Cai JP, Li Y, Wei RL. A meta-analysis of topical prostaglandin analogs in the treatment of chronic angle-closure glaucoma. J Glaucoma. 2009;18:652-657.

44. Cheng JW, Cai JP, Wei RL. Meta-analysis of medical intervention for normal tension glaucoma. Ophthalmology. 2009;116:1243-1249.

45. Aptel F, Cucherat M, Denis P. Efficacy and tolerability of prostaglandin analogs: a meta-analysis of randomized controlled clinical trials J Glaucoma. 2008;17:667-673.

46. Cheng JW, Wei RL. Meta-analysis of 13 randomized controlled trials comparing bimatoprost with latanoprost in patients with elevated intraocular pressure. Clin Ther. 2008;30:622-632.

47. van der Valk R, Webers CA, Schouten JS, Zeegers MP, Hendrikse F, Prins MH. Intraocular pressure-lowering effects of all commonly used glaucoma drugs: a meta-analysis of randomized clinical trials. Ophthalmology. 2005;112:1177-1185.

48. Stewart WC, Konstas AG, Nelson LA, Kruft B. Meta-analysis of 24-hour intraocular pressure studies evaluating the efficacy of glaucoma medicines. Ophthalmology. 2008;115:1117-1122.

49. Denis P, Lafuma A, Khoshnood B, Mimaud V, Berdeaux G. A metaanalysis of topical prostaglandin analogues intra-ocular pressure lowering in glaucoma therapy. Curr Med Res Opin. 2007;23:601-608.

50. Cucherat M, Stalmans I, Rouland JF. Relative efficacy and safety of preservative-free latanoprost (T2345) for the treatment of open-angle glaucoma and ocular hypertension: an adjusted indirect comparison meta-analysis of randomized clinical trials. J Glaucoma. 2014;23: e69-e75.

51. Rossetti L, Gandolfi S, Traverso C, et al. An evaluation of the rate of nonresponders to latanoprost therapy. J Glaucoma. 2006;15:238-243.

52. Hedman K, Alm A. A pooled-data analysis of three randomized, double-masked, six-month clinical studies comparing the intraocular pressure reducing effect of latanoprost and timolol. Eur J Ophthalmol. 2000;10:95-104

53. Hedman K, Alm A, Gross RL. Pooled-data analysis of three randomized, double-masked, six-month studies comparing intraocular pressurereducing effects of latanoprost and timolol in patients with ocular hypertension. J Glaucoma. 2003;12:463-465.
54. Zhang WY, Po AL, Dua HS, Azuara-Blanco A. Meta-analysis of randomised controlled trials comparing latanoprost with timolol in the treatment of patients with open angle glaucoma or ocular hypertension. Br J Ophthalmol. 2001;85:983-990.

55. Maeda-Chubachi T, Chi-Burris K, Simons BD, et al. Comparison of latanoprost and timolol in pediatric glaucoma: a phase 3, 12-week, randomized, double-masked multicenter study. Ophthalmology. 2011;118:2014-2021.

56. Hodge WG, Lachaine J, Steffensen I, et al. The efficacy and harm of prostaglandin analogues for IOP reduction in glaucoma patients compared to dorzolamide and brimonidine: a systematic review. Br J Ophthalmol. 2008;92:7-12.

57. Einarson TR, Kulin NA, Tingey D, Iskedjian M. Meta-analysis of the effect of latanoprost and brimonidine on intraocular pressure in the treatment of glaucoma. Clin Ther. 2000;22:1502-1515.

58. Fung AT, Reid SE, Jones MP, Healey PR, McCluskey PJ, Craig JC. Meta-analysis of randomised controlled trials comparing latanoprost with brimonidine in the treatment of open-angle glaucoma, ocular hypertension or normal-tension glaucoma. $\mathrm{Br} \mathrm{J} \mathrm{Ophthalmol.}$ 2007;91:62-68.

59. Higginbotham EJ, Diestelhorst M, Pfeiffer N, Rouland JF, Alm A. The efficacy and safety of unfixed and fixed combinations of latanoprost and other antiglaucoma medications. Surv Ophthalmol. 2002;47 Suppl 1: S133-S140.

60. Cheng JW, Cheng SW, Gao LD, Lu GC, Wei RL. Intraocular pressure-lowering effects of commonly used fixed-combination drugs with timolol: a systematic review and meta-analysis. PLoS One. 2012; 7:e45079.

61. Toris CB, Alm A, Camras CB. Latanoprost and cholinergic agonists in combination. Surv Ophthalmol. 2002;47 Suppl 1:S141-S147.

62. O'Connor DJ, Martone JF, Mead A. Additive intraocular pressure lowering effect of various medications with latanoprost. Am J Ophthalmol. 2002;133:836-837.

63. Lindén C, Alm A. Latanoprost and physostigmine have mostly additive ocular hypotensive effects in human eyes. Arch Ophthalmol. 1997;115:857-861.

64. Cheng JW, Xi GL, Wei RL, Cai JP, Li Y. Efficacy and tolerability of latanoprost compared to dorzolamide combined with timolol in the treatment of patients with elevated intraocular pressure: a metaanalysis of randomized, controlled trials. J Ocul Pharmacol Ther. 2009;25:55-64.

65. Fechtner RD, Godfrey DG, Budenz D, Stewart JA, Stewart WC, Jasek MC. Prevalence of ocular surface complaints in patients with glaucoma using topical intraocular pressure-lowering medications. Cornea. 2010;29:618-621.

66. Honrubia F, García-Sánchez J, Polo V, de la Casa JM, Soto J. Conjunctival hyperaemia with the use of latanoprost versus other prostaglandin analogues in patients with ocular hypertension or glaucoma: a meta-analysis of randomised clinical trials. Br J Ophthalmol. 2009;93:316-321.

67. Alm A, Grierson I, Shields MB. Side effects associated with prostaglandin analog therapy. Surv Ophthalmol. 2008;53 Suppl 1: S93-S105.

68. Stewart WC, Kolker AE, Stewart JA, Leech J, Jackson AL Conjunctival hyperemia in healthy subjects after short-term dosing with latanoprost, bimatoprost, and travoprost. Am J Ophthalmol. 2003; 135:314-320.

69. Walters TR, DuBiner HB, Carpenter SP, Khan B, VanDenburgh AM; Bimatoprost Circadian IOP Study Group. 24-Hour IOP control with once-daily bimatoprost, timolol gel-forming solution, or latanoprost: a 1-month, randomized, comparative clinical trial. Surv Ophthalmol. 2004;49 Suppl 1:S26-S35.

70. Schuman JS. Short- and long-term safety of glaucoma drugs. Expert Opin Drug Saf. 2002;1:181-194.

71. Feldman RM. Conjunctival hyperemia and the use of topical prostaglandins in glaucoma and ocular hypertension. J Ocul Pharmacol Ther. 2003;19:23-35. 
72. Schulze MM, Hutchings N, Simpson TL. Grading bulbar redness using cross-calibrated clinical grading scales. Invest Ophthalmol Vis Sci. 2011;52:5812-5817.

73. Schwartz GF, Tan J, Kotak S. Hyperemia-associated costs of medication changes in glaucoma patients treated initially with prostaglandin analogs. J Ocular Pharmacol Ther. 2009;25:555-561.

74. Tressler CS, Wiseman RL, Dombi TM, et al. Lack of evidence for a link between latanoprost use and malignant melanoma: an analysis of safety databases and a review of the literature. Br J Ophthalmol. 2011;95:1490-1495.

75. Stjernschantz JW, Albert DM, Hu DN, Drago F, Wistrand PJ. Mechanism and clinical significance of prostaglandin-induced iris pigmentation. Survey Ophthalmol. 2002;47 Suppl 1:S162-S175.

76. Inoue K, Shiokawa M, Wakakura M, Tomita G. Deepening of the upper eyelid sulcus caused by 5 types of prostaglandin analogs. J Glaucoma. 2013;22:626-631.

77. Aihara M, Shirato S, Sakata R. Incidence of deepening of the upper eyelid sulcus after switching from latanoprost to bimatoprost. Jpn $J$ Ophthalmol. 2011;55:600-604.

78. Hedner J, Everts B, Mooller CS. Latanoprost and respiratory function in asthmatic patients: randomized, double-masked, placebo- controlled crossover evaluation. Arch Ophthalmol. 1999;117:1305-1309.

79. Featherstone RL, Robinson C, Holgate ST, Church MK. Evidence for thromboxane receptor mediated contraction of guinea-pig and human airways in vitro by prostaglandin (PG) D2, 9 alpha, 11 beta-PGF2 and PGF2 alpha. Naunyn Schmiedebergs Arch Pharmacol. 1990;341: 439-443.

80. Erkin EF, Celik P, Kayikçioğlu O, Deveci HM, Sakar A. Effects of latanoprost and betaxolol on cardiovascular and respiratory status of newly diagnosed glaucoma patients. Ophthalmologica. 2006;220: 332-337.

81. Quigley HA. Improving eye drop treatment for glaucoma through better adherence. Optom Vis Sci. 2008;85:374-375.

82. Reardon G, Kotak S, Schwartz GF. Objective assessment of compliance and persistence among patients treated for glaucoma and ocular hypertension: a systematic review. Patient Prefer Adherence. 2011;5:441-463.

83. Yeaw J, Benner JS, Walt JG, Sian S, Smith DB. Comparing adherence and persistence across 6 chronic medication classes. J Manag Care Pharm. 2009;15:728-740.

84. Gurwitz JH, Glynn RJ, Monane M, et al. Treatment for glaucoma: adherence by the elderly. Am J Public Health. 1993;83:711-716.

85. Robin AL, Covert D. Does adjunctive glaucoma therapy affect adherence to the initial primary therapy? Ophthalmology. 2005;112:863-868.

86. Odberg T, Jakobsen JE, Hultgren SJ, Halseide R. The impact of glaucoma on the quality of life of patients in Norway. I. Results from a self-administered questionnaire. Acta Ophthalmol Scand. 2001;79: $116-120$.

87. Nordmann JP, Auzanneau N, Ricard S, Berdeaux G. Vision related quality of life and topical glaucoma treatment side effects. Health Qual Life Outcomes. 2003;1:75.

88. Beckers HJ, Schouten JS, Webers CA, van der Valk R, Hendrikse F. Side effects of commonly used glaucoma medications: comparison of tolerability, chance of discontinuation, and patient satisfaction. Graefes Arch Clin Exp Ophthalmol. 2008;246:1485-1490.

89. Pellinen P, Huhtala A, Tolonen A, Lokkila J, Mäenpää J, Uusitalo H. The cytotoxic effects of preserved and preservative-free prostaglandin analogs on human corneal and conjunctival epithelium in vitro and the distribution of benzalkonium chloride homologs in ocular surface tissues in vivo. Curr Eye Res. 2012;37:145-154.

90. Baudouin C, Renard JP, Nordmann JP, et al. Prevalence and risk factors for ocular surface disease among patients treated over the long term for glaucoma or ocular hypertension. Eur J Ophthalmol. Epub June 11, 2012.

91. Pauly A, Brignole-Baudouin F, Guenoun JM, et al. Comparative study of topical anti-allergic eye drops on human conjunctiva-derived cells: responses to histamine and IFN gamma and toxicological profiles. Graefes Arch Clin Exp Ophthalmol. 2007;245:534-546.
92. Cui L, Shen M, Wang J, et al. Age-related changes in tear menisci imaged by optical coherence tomography. Optom Vis Sci. 2011;88: 1214-1219.

93. Guillon M, Maïssa C. Tear film evaporation: effect of age and gender. Contb Lens Anterior Eye. 2010;33:171-175.

94. Schaumberg DA, Nichols JJ, Papas EB, Tong L, Uchino M, Nichols KK. The international workshop on meibomian gland dysfunction: report of the subcommittee on the epidemiology of, and associated risk factors for MGD. Invest Ophthalmol Vis Sci. 2011;52: 1994-2005.

95. Schaumberg DA, Dana R, Buring JE, Sullivan DA. Prevalence of dry eye disease among US men: estimates from the Physicians' Health Studies. Arch Ophthalmol. 2009;127:763-768.

96. Pisella PJ, Pouliquen P, Baudouin C. Prevalence of ocular symptoms and signs with preserved and preservative free glaucoma medication. Br J Ophthalmol. 2002;86:418-423.

97. Jaenen N, Baudouin C, Pouliquen P, Manni G, Figueiredo A, Zeyen T. Ocular symptoms and signs with preserved and preservative-free glaucoma medications. Eur J Ophthalmol. 2007;17:341-349.

98. Bron A, Chiambaretta F, Pouliquen P, Rigal D, Rouland JF. [Efficacy and safety of substituting a twice-daily regimen of timolol with a single daily instillation of nonpreserved beta-blocker in patients with chronic glaucoma or ocular hypertension]. J Fr Ophtalmol. 2003;26:668-674. French.

99. Rouland JF. Etude CARAT: acceptabilité d'un collyre bêtabloquant sans conservateur dans le traitement du glaucome. Réflexions Ophtalmologiques. 2011;150:43-46.

100. Rowe RC, Sheskey PJ, Owen SC. Handbook of Pharmaceutical Excipients. 5th ed. McGraw-Hill Medical.

101. Daull P, Buggage R, Lambert G, et al. A comparative study of a preservative-free latanoprost cationic emulsion (Catioprost) and a BAK-preserved latanoprost solution in animal models. J Ocul Pharmacol Ther. 2012;28:515-523.

102. Rouland JF, Traverso CE, Stalmans I, et al. Efficacy and safety of preservative-free latanoprost eyedrops, compared with BAK-preserved latanoprost in patients with ocular hypertension or glaucoma. $\mathrm{Br} J$ Ophthalmol. 2013;97:196-200.

103. Dasgupta S, Oates V, Bookhart BK, Vaziri B, Schwartz GF, Mozaffari E. Population-based persistency rates for topical glaucoma medications measured with pharmacy claims data. Am J Manag Care. 2002;8(Supp1 10):S255-S261.

104. Shaya FT, Mullins CD, Wong W, Cho J. Discontinuation rates of topical glaucoma medications in a managed care population. Am J Manag Care. 2002;8(Suppl 10):S271-S277.

105. Spooner JJ, Bullano MF, Ikeda LI, et al. Rates of discontinuation and change of glaucoma therapy in a managed care setting. Am J Manag Care. 2002;8(Suppl 10):S262-S270.

106. Reardon G, Schwartz GF, Mozaffari E. Patient persistency with ocular prostaglandin therapy: a population-based, retrospective study. Clin Ther. 2003;25:1172-1185.

107. Diestelhorst M, Schaefer CP, Beusterien KM, et al. Persistency and clinical outcomes associated with latanoprost and beta-blocker monotherapy: evidence from a European retrospective cohort study. Eur $J$ Ophthalmol. 2003;13 Supp1 4:S21-S29.

108. Day DG, Schacknow PN, Sharpe ED, et al. A persistency and economic analysis of latanoprost, bimatoprost, or beta-blockers in patients with open-angle glaucoma or ocular hypertension. J Ocul Pharmacol Ther. 2004;20:383-392.

109. Haverkamp F, Wuensch S, Fuchs M, Stewart WC. Intraocular pressure, safety and quality of life in glaucoma patients switching to latanoprost from adjunctive and monotherapy treatments. Eur J Ophthalmol. 2004;14:407-415.

110. Reardon G, Schwartz GF, Mozaffari E. Patient persistency with topical ocular hypotensive therapy in a managed care population. Am J Ophthalmol. 2004;137(Suppl 1):S3-S12.

111. Schwartz GF, Reardon G, Mozaffari E. Persistency with latanoprost or timolol in primary open-angle glaucoma suspects. Am J Ophthalmol. 2004;137(Suppl 1):S13-S16. 
112. Wilensky J, Fiscella RG, Carlson AM, Morris LS, Walt J. Measurement of persistence and adherence to regimens of IOP-lowering glaucoma medications using pharmacy claims data. Am J Ophthalmol. 2006;141(Suppl 1):S28-S33.

113. Bhosle MJ, Reardon G, Camacho FT, Anderson RT, Balkrishnan R. Medication adherence and health care costs with the introduction of latanoprost therapy for glaucoma in a Medicare managed care population. Am J Geriatr Pharmacother. 2007;5:100-111.

114. Zimmerman TJ, Hahn SR, Gelb L, Tan H, Kim EE. The impact of ocular adverse effects in patients treated with topical prostaglandin analogs: changes in prescription patterns and patient persistence. J Oc Pharm Ther. 2009;25:145-152.

115. Arias A, Schargel K, Ussa F, Canut MI, Robles AY, Sánchez BM. Patient persistence with first-line antiglaucomatous monotherapy. Clin Ophthalmol. 2010;4:261-267.
116. Friström B, Uusitalo H. A randomized, 36-month, post-marketing efficacy and tolerability study in Sweden and Finland of latanoprost versus non-prostaglandin therapy in patients with glaucoma or ocular hypertension. Acta Ophthalmol. 2010;88:37-43.

117. Reardon G, Schwartz GF, Kotak S. Persistence on prostaglandin ocular hypotensive therapy: an assessment using medication possession and days covered on therapy. BMC Ophthalmol. 2010;10:5.

118. Rahman MQ, Abeysinghe SS, Kelly S, et al. Persistence of glaucoma medical therapy in the Glasgow Glaucoma Database. Br J Ophthalmol. 2011;95:966-970.
Clinical Ophthalmology

\section{Publish your work in this journal}

Clinical Ophthalmology is an international, peer-reviewed journal covering all subspecialties within ophthalmology. Key topics include: Optometry; Visual science; Pharmacology and drug therapy in eye diseases; Basic Sciences; Primary and Secondary eye care; Patien Safety and Quality of Care Improvements. This journal is indexed on

Submit your manuscript here: http://www.dovepress.com/clinical-ophthalmology-journal

\section{Dovepress}

PubMed Central and CAS, and is the official journal of The Society of Clinical Ophthalmology (SCO). The manuscript management system is completely online and includes a very quick and fair peer-review system, which is all easy to use. Visit http://www.dovepress.com/ testimonials.php to read real quotes from published authors. 